\title{
Biochemistry and Localization of Somatostatin in the Retina
}

\author{
TADATAKA YAMADA \\ Department of Internal Medicine, The University of Michigan Medical School, Ann Arbor, \\ MI 48109-0362, USA
}

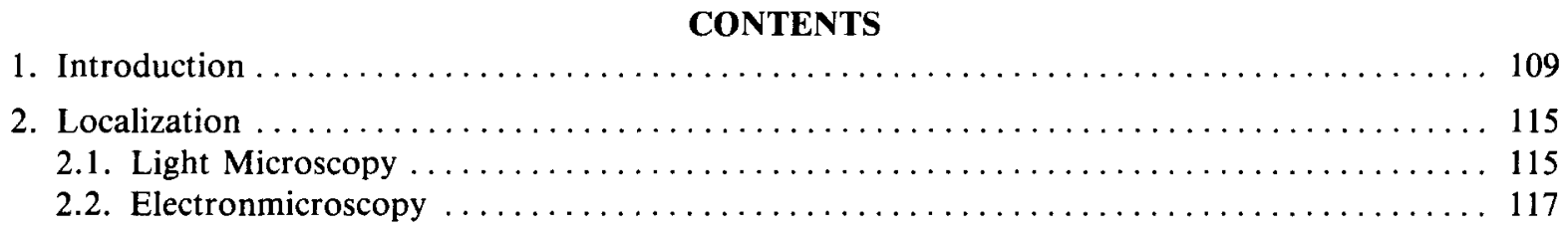

3. Characterization of Molecular Forms $\ldots \ldots \ldots \ldots \ldots \ldots \ldots \ldots \ldots \ldots \ldots \ldots \ldots \ldots \ldots \ldots \ldots$

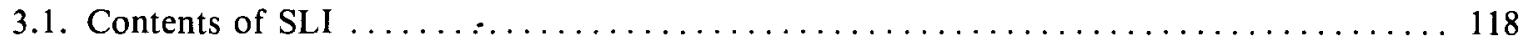

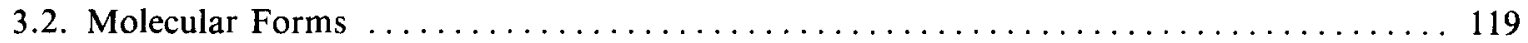

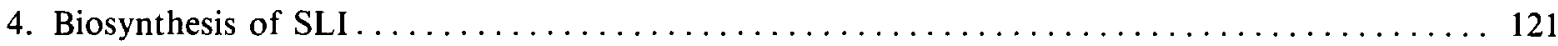

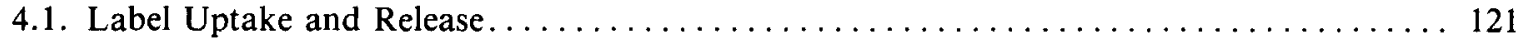

4.2. Post-Translational Processing of SLI $\ldots \ldots \ldots \ldots \ldots \ldots \ldots \ldots \ldots \ldots \ldots \ldots \ldots \ldots \ldots \ldots$

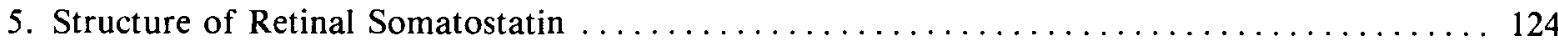

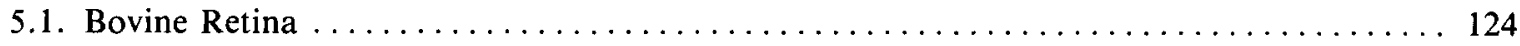

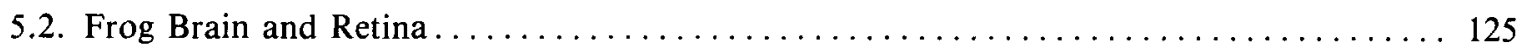

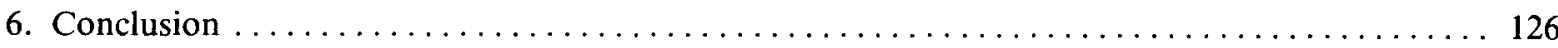

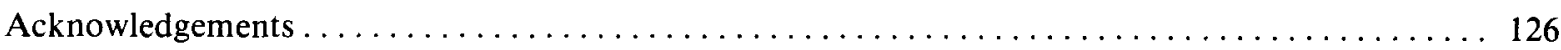

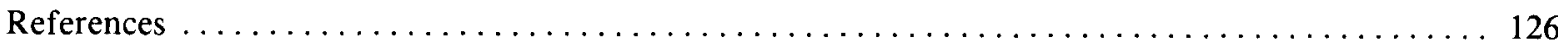

\section{INTRODUCTION}

In 1902 Bayliss and Starling described the first hormone, secretin, when they characterized a pancreatic stimulant that was secreted into the circulation in response to duodenal acidification. In subsequent studies this and many other hormones were identified as small polypeptides with widespread distribution throughout the body. Many of these polypeptides have been proposed as neurotransmitters in the peripheral and central nervous systems. However, the evidence for a neurotransmitter function for these peptides has been limited primarily to simple localization by immunologic means to nerve tissues. Many of the peptides in question have not been purified from nerves and thus the relationship of their immunoreactivities to chemical structures is unknown.

The complexity of the brain makes neuropeptide studies such as biosynthesis and release experiments, correlation of localization to known cellular function on the basis of electrophysiologic studies, and determination of specific cellular receptors difficult to perform as well as to interpret. The retina, however, provides an ideal system for further exploration of the neural function of brain peptides (Ames and 


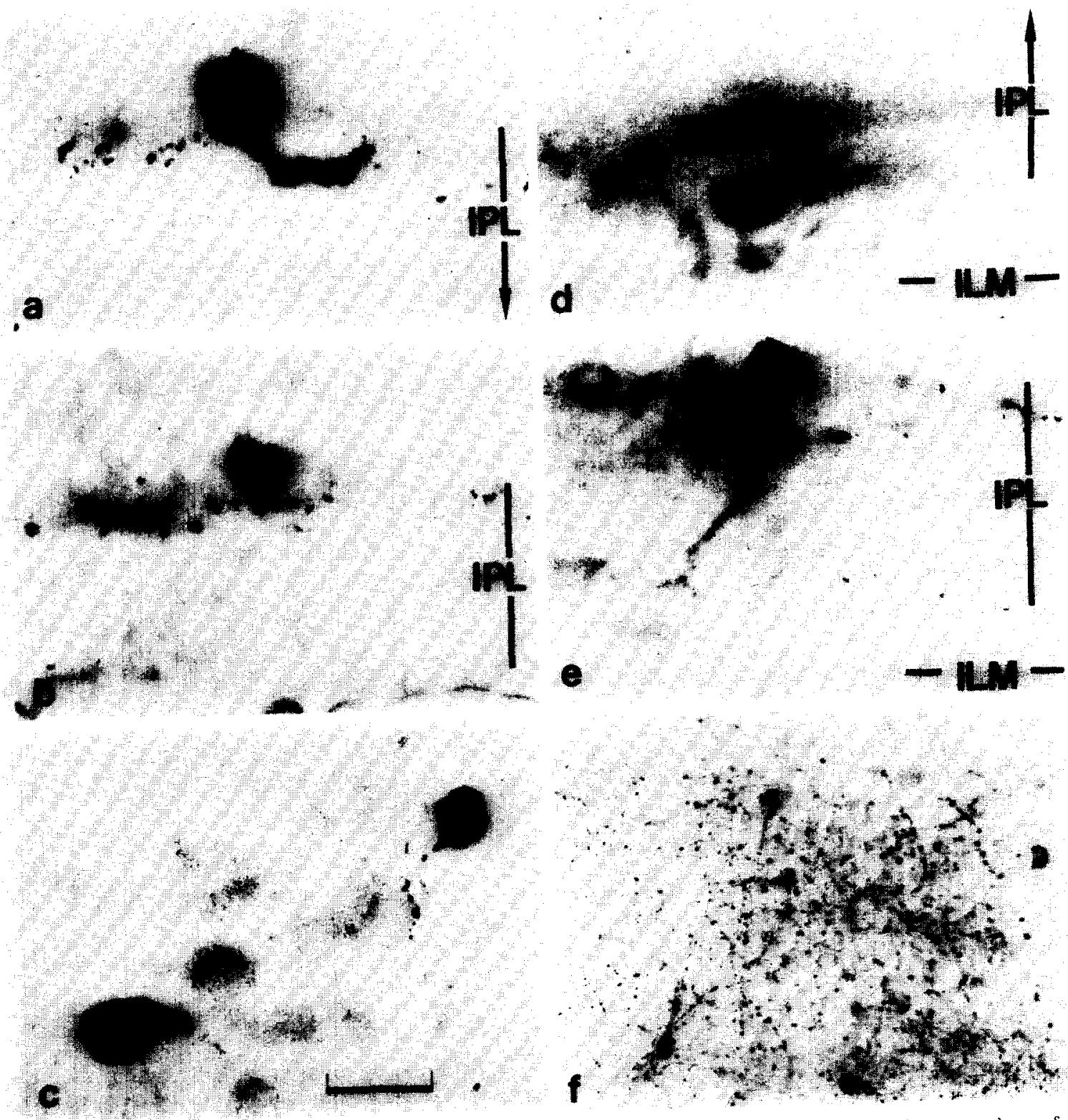

FIG. 1. SLI-containing cell bodies and processes stained by indirect immunofluorescence in $10 \mu \mathrm{m}$ frozen sections of ( goldfish retina. The calibration mark the inner limiting membranes (ILM) are marked by the horizonal lines. (a) Large are marked by the vertical lines and the inner liming me (SAal). (b) Fine varicose fibers forming a plexus in the distal unbranched process extending from a large round cell body (SAa1). (b) Fal and SAa2 cells with their processes in a tangential IPL originating from a small spherical perikaryon (SAa2). (c) SAal and SAa2 cesses from the smaller cells. (d) Cell in the section, illustrating the origin of thick processes from the large cells and thin processes from with processes descending into the ganglion cell layer (SGb) associated with smooth processes. (e) Pyer view of tangential section of retina, illustrating the most proximal sublamina of the IPL (Sab). ( $\mathrm{f}$ ) Low-power The names of the cell bodies containing SLI were derived predominance of fine varicose fibers amid numerous perikarya. The names of thell layer; $a$ and $b$ refer to the location of the as follows: $\mathrm{S}=$ somatostatin-containing; $\mathrm{A}=$ amarine 2 refer to the subtypes. Hence, SAa2 refers to somatostatin-containing

processes in the inner plexiform layer; and 1 and 2 refer to the subtypes. Hina a, type 2 . (From Yamada et al., 1980). 


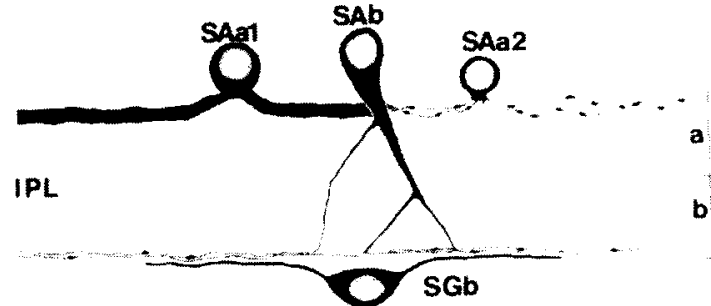

FIG. 2. Diagram of four types of SLI-containing cell bodies with their processes, Sublaminae $a$ and $b$ of the inner plexiform layer (IPL) are marked. (From Yamada et al., 1980).

Nesbitt, 1981). It is an integral but discreet component of the brain which can be isolated without damage to its intrinsic neurons and can be maintained in organ culture for prolonged periods. Moreover, the anatomy, physiology, and pharmacology of the retina have been extensively characterized. Each of the major cell types have been studied by intracellular recording (Kaneko, 1979). Because the retina responds to light, it can be activated by the same light stimuli in vitro that it responds to in vivo. Since discreet populations of retinal cells can be activated with different light or pharmacologic stimuli, the retina provides an unique opportunity in which to perform parallel electrophysiological and biochemical studies.

For these reasons, a number of investigators initiated studies to localize neuroactive peptides in the retina. Schaeffer et al. (1977) first found thyrotropin releasing hormone-like immunoreactivity (TRH-LI) by radioimmunoassay in extracts of rat retina and observed that levels of this peptide increased during exposure of animals to light. Since these initial observations, a number of peptides have been localized to the retina, primarily by immunohistochemical techniques, as reviewed by Stell et al. (1980) and Brecha (1983). Among the peptides that my collaborators and I have examined is somatostatin.

The isolation of somatostatin was initially reported in 1973 by investigators in Guillemin's laboratory as an unexpected dividend in the search for the hypothalamic releasing factor responsible for regulation of pituitary growth hormone secretion (Brazeau et al., 1973). In their early attempts to isolate thyrotropin releasing factor and luteinizing hormone releasing factor, they observed a consistent inhibition of growth hormone secretion from dispersed rat pituitary cells in culture by fractions of their hypothalamic extracts, much as Krulich et al. (1968) had described several years earlier. Because of the reproducibility of their findings, Brazeau et al. set out to purify this somatotropin-release inhibiting factor (SRIF) from a chloroform-methanol-glacial acetic acid extract of 500,000 sheep hypothalami and isolate the cyclic tetradecapeptide that we know today as somatostatin. Following these initial studies, numerous additional pharmacological actions of somatostatin were described in rapid succession, not only on pituitary hormone secretion, but on functions of such diverse organs as the pancreatic islets and the stomach. It was not until 1975, however, that Arimura et al. (1975) desribed the first radioimmunoassay for somatostatin and with it, the first hints as to the ubiquitous distribution of the peptide in its multiple molecular forms were provided. Today, somatostatin-like immunoreactivity (SLI) is known to be present in virtually every tissue in the body, and as aptly described by Reichlin (1983), "the names of the organisms shown to contain immunoreactive somatostatin read like the passenger's list of Noah's ark', and include not only the familiar vertebrates, but also protochordates, plants, protozoa, and even prokaryotes.

The primary evidence that somatostatin is a neurotransmitter is that somatostatin-like immunoreactivity (SLI) has been identified in axons and nerve cell bodies of primary sensory neurons (Hokflet et al., 1975), sympathetic neurons (Hokfelt et al., 1977), and intrinsic neurons of the intestines (Hokfelt et al., 1975; Costa et al., 1977), as well as in neurons of the central nervous system (Krisch, 1978). In addition, SLI has been localized to secretory granules within the median eminence (Pelletier et al., 1974) and terminal synaptosomes of neurons of the hypothalamus (Epelbaum et al., 1977; Styne et al., 1977). SLI release from nerve tissues by depolarization has been shown to be calciumdependent (Iverson et al., 1978) and electrophysiological studies have demonstrated that somatostatin in low concentrations affects the discharge rate of neurons in various regions of the 


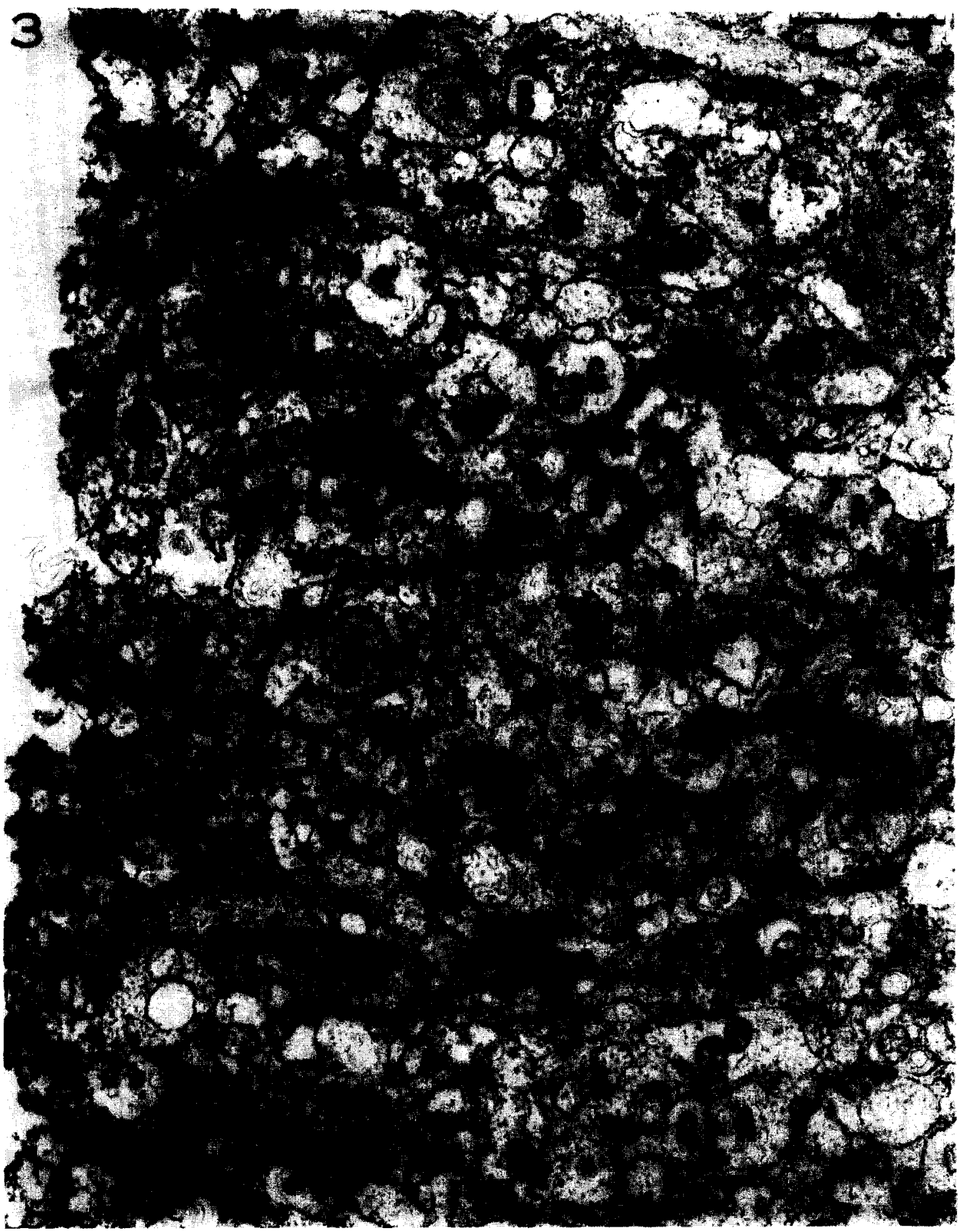

F1G. 3. A vertical section of sublamina a of the inner plexiform layer. The edge of the original $100 \mu \mathrm{m}$ tissue chopper section is at the left. Three labeled amacrine cell processes are marked with arrowheads. The calibration bar is $2 \mu \mathrm{m}$. Abbreviations: A, amacrine cell process; B, bipolar cell axon termina; G, ganglion cell dendrite; The letter symbols are used in succeeding figures. (From Marshak et al., 1984). 


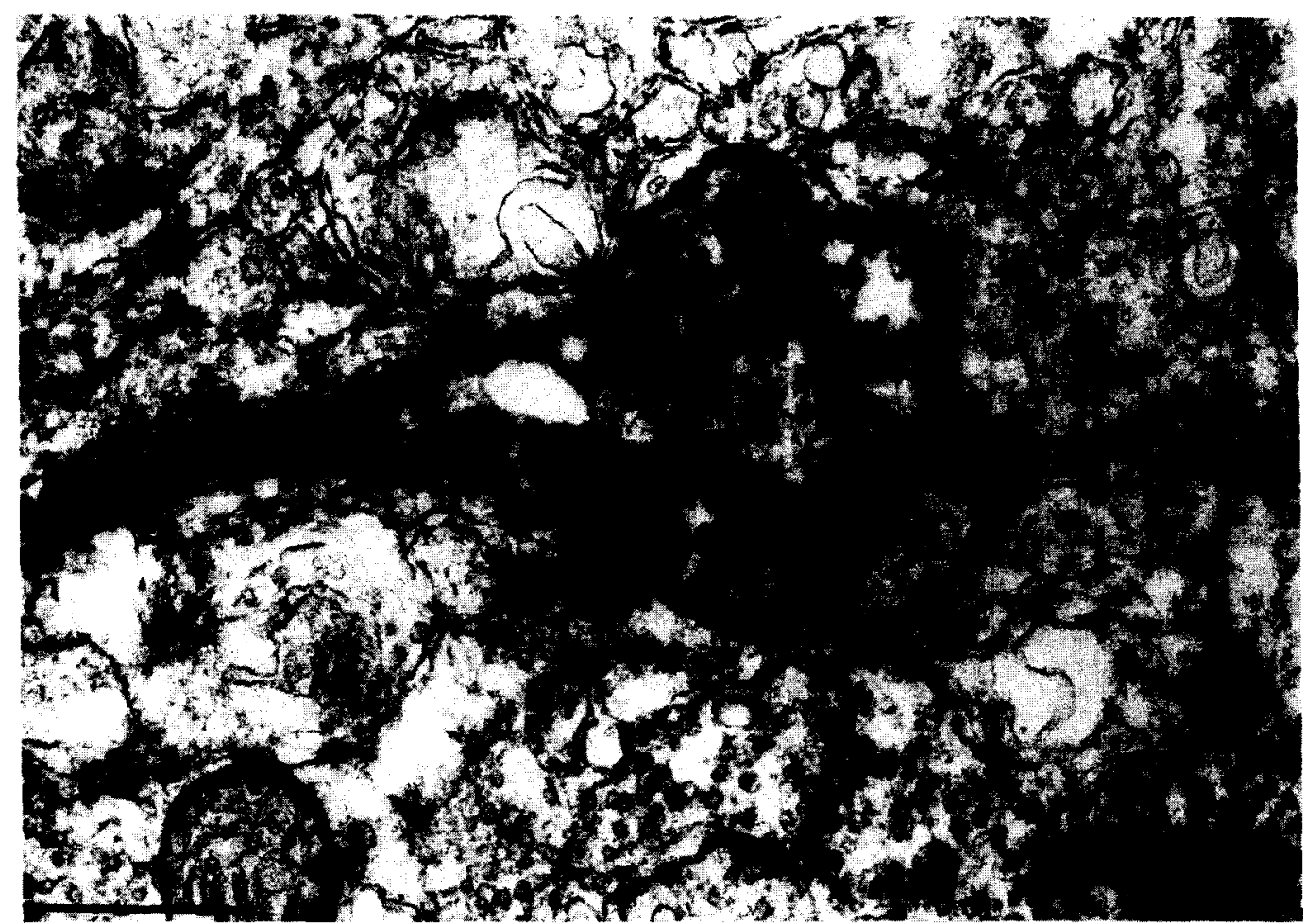

FIG. 4. A vertical section through sublamina $b$ of the inner plexiform layer. The labeled process increased in diameter near the center of the micrograph and is presynaptic to a presumed ganglion cell dendrite $(\mathrm{G})$ at the site between the arrows. The postsynaptic process did not contain any presynaptic specializations in the 12 adjacent, serial sections. The thick arrowhead indicates a large, dense-cored vesicle. The calibration bar is $0.5 \mu \mathrm{m}$. (From Marshak et al., 1984).

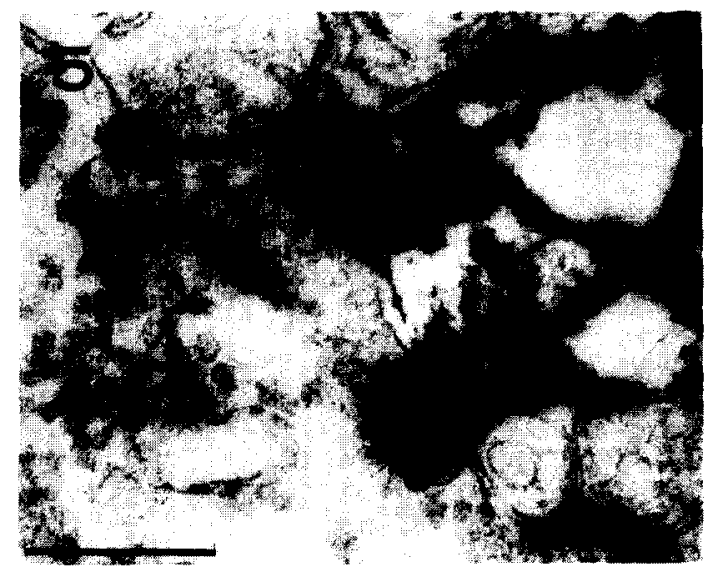

FIG. 5. A vertical section through sublamina b of the inner plexiform layer. The site of synaptic input from the labeled amacrine cell process is between the arrows. The postsynaptic cell was identified as a bipolar cell by its characteristic indented shape, high synaptic vesicle density, high cytoplasmic electron density, and synaptic ribbon (arrowhead). The calibration bar is $1 \mu \mathrm{m}$. (From Marshak et al., 1984).

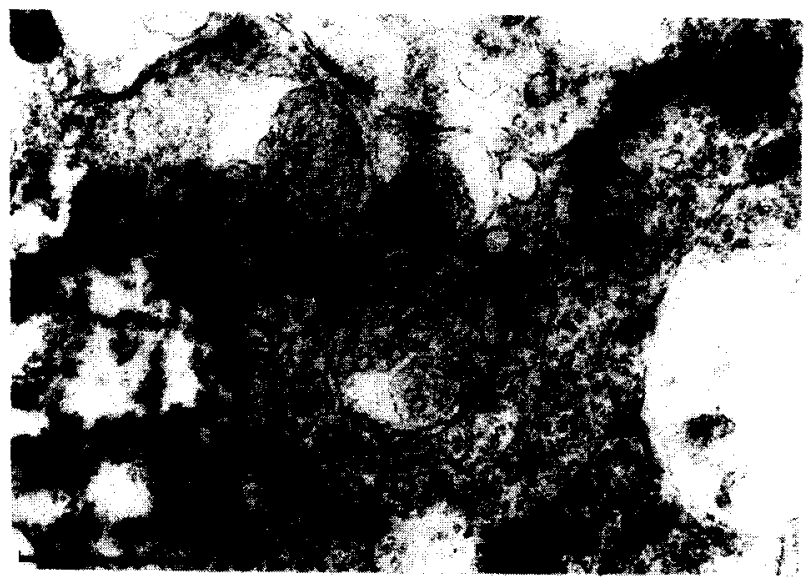

FIG, 6. A vertical section through sublamina a of the inner plexiform layer. The synaptic ribbon (arrowhead) of this bipolar cell axon terminal has been sectioned tangentially. This terminal is presynaptic to the labeled amacrine cell process below. The calibration bar is $0.5 \mu \mathrm{m}$. (From Marshak et al., 1984). 


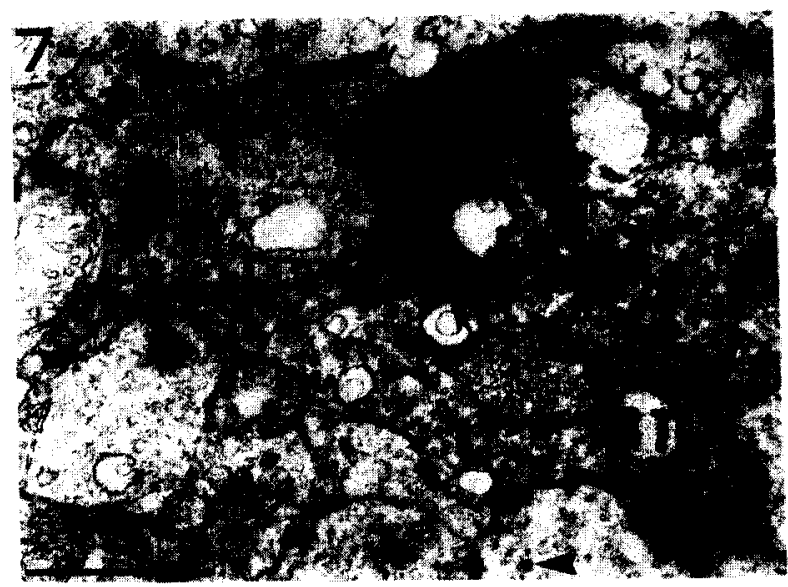

FiG. 7. A tangential section through sublamina a of the inner plexiform layer. A bipolar cell telodendron receives a synapse from a labeled amacrine cell process at the site between the arrows. This telodendron was traced to the terminal of a large, mixed, rod-cone bipolar cell in adjacent sections. The calibration bar is $1 \mu \mathrm{m}$. B'T, bipolar cell telodendron. (From Marshak et al., 1984).

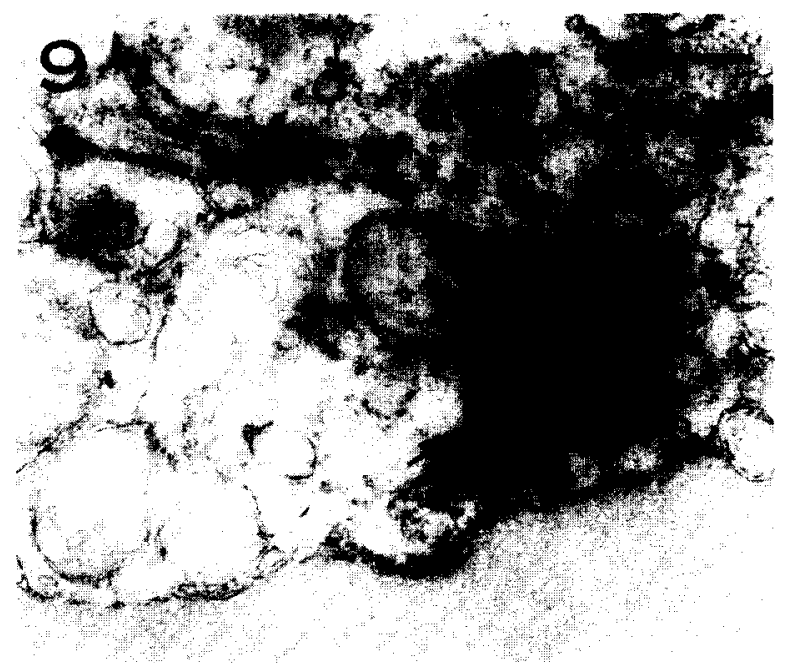

FIG. 9. A vertical section through sublamina a of the inner plexiform layer. The unlabeled amacrine cell process contains a few small, electron-lucent vesicles which are not clustered near the site, between the arrowheads, where it receives a synaptic contact from the labeled amacrine cell process. The calibration bar is $0.5 \mu \mathrm{m}$. As, amacrine cell soma. (From Marshak et al., 1984).

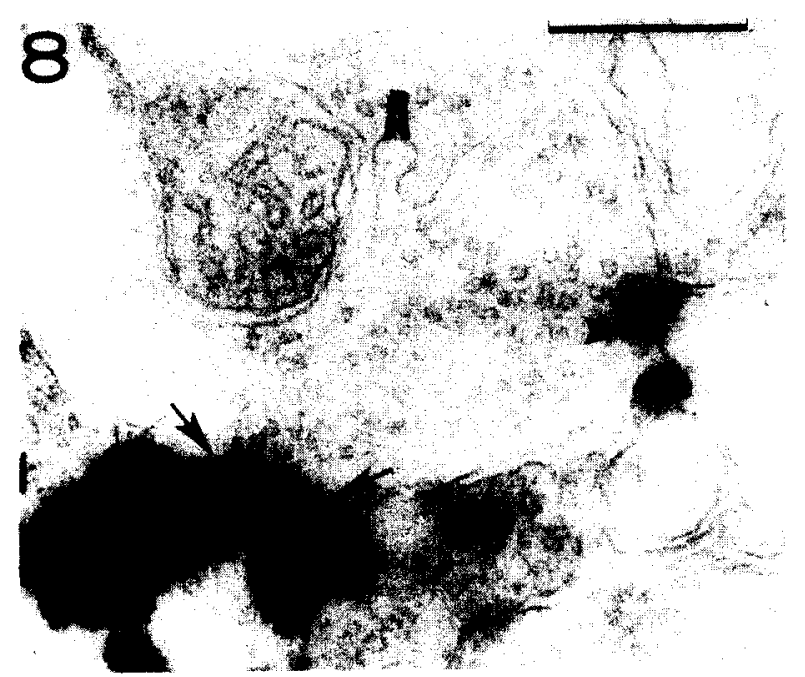

FIG. 8. A vertical section through sublamina b of the inner plexiform layer. The amacrine cell contains small, electron-lucent vesicles, which are clustered at the arrowhead, where it is presynaptic to an unlabeled process and near the site between the arrows, where it is presynaptic to the labeled amacrine cell process. The calibration bar is $0.5 \mu \mathrm{m}$. (From Marshak et al., 1984).

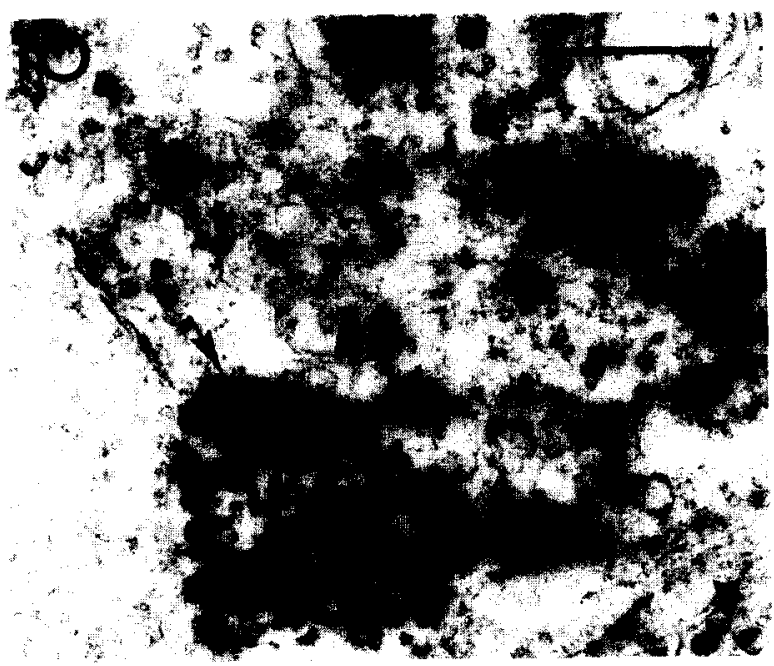

FIG. 10. A vertical section through the border between the inner nuclear and inner plexiform layers. The soma of this amacrine cell was identified by its position in the most proximal row of the inner nuclear layer. It receives a synaptic contact from the labeled amacrine cell process at the site between the arrows. The arrowhead indicates unlabeled, large, dense-cored vesicles in an adjacent process. The calibration bar is $0.5 \mu \mathrm{m}$. (From Marshak et al., 1984). 
TABLE. 1. Identified Synapses of Amacrine Cells Containing $S L I^{*}$

\begin{tabular}{lcc}
\hline Type to SLI cells & Sublamina a & Sublamina b \\
\hline Presynaptic & & \\
Bipolar & $2(12 \%)$ & $1(11 \%)$ \\
Amacrine & $15(88 \%)$ & $8(89 \%)$ \\
Postsynaptic & & \\
Bipolar & $2(5 \%)$ & $2(8 \%)$ \\
Amacrine & $23(53 \%)$ & $15(58 \%)$ \\
Ganglion & $18(42 \%)$ & $9(35 \%)$ \\
\hline
\end{tabular}

*Table 1 summarizes 95 identified synapses made by labeled cells -31 from serial sections in the tangential plane and 64 from serial sections in the vertical plane. In each column the number of contacts of each type observed is given followed in parentheses by the percentage of the total presynaptic or postsynaptic in that sublamina. (From Marshak et al., 1984).

brain (Dodd and Kelly, 1978; Ioffe et al., 1978; Renand et al., 1975), dorsal horn of the spinal cord (Randic and Miletic, 1978), and myenteric plexus of the intestines (Guillemin, 1976). Furthermore, a system for rapid sequestration and degradation of somatostatin has been identified in brain capillaries (Pardridge et al., 1985).

During the past several years my principal collaborators (David Marshak, Scott Basinger, and Mimi Takami) and I have concentrated on extending our initial description of SLI in discreet cells in the amacrine cell layer of the retina (Yamada et al., 1980) to ultrastructional characterization of the SLI-containing retinal cell (Marshak et al., 1986), examination of the pathways of SLI biosynthesis (Yamada and Basinger, 1982), and characterization (Marshak et $a l ., 1984$ ) and isolation of retinal SLI (Marshak et al., 1983; Takami et al., 1985). We hope that these studies will provide the groundwork upon which future physiological studies with somatostatin peptides of known structure can be undertaken by ourselves as well as by others. In addition, we hope that our observations have shed light on the nature of somatostatin molecular biology by providing an understanding of the pathways of post-translational processing of the somatostatin precursor.

\section{LOCALIZATION}

\subsection{Light Microscopy}

Although SLI has been found in retinas from a variety of species (Stell et al., 1980; Brecha, 1983), this review will focus on the localization of SLI in the goldfish since extensive characterization of SLI-containing neurons in the retina at both the light and electronmicroscopic level has only been achieved in these species.

For light microscopic studies, the enucleated eyes of light-adapted goldfish were sectioned longitudinally through the optic disc and those of dark-adapted fish were sectioned equatorially. The retinas were dissected free and fixed in $\mathbf{4 \%}$ (wt/vol.) paraformaldehyde in a phosphatebuffered saline (PBS) solution $(0.05 \mathrm{M}$ sodium phosphate, $0.4 \mathrm{M} \mathrm{NaCl}, \mathrm{pH} 7.2$ ) for $16 \mathrm{hr}$. After incubation in $30 \%$ sucrose in PBS for $24 \mathrm{hr}$, the tissues were frozen, then $10 \mu \mathrm{m}$ sections were obtained and mounted on gelatin-coated slides. The sucrose was removed by rinsing in PBS and the specimens were incubated for $2 \mathrm{hr}$ at $37^{\circ}$ with somatostatin antisera and then for $30 \mathrm{~min}$ in fluorescein isothiocyanate conjugated goat antirabbit gamma globulin. Appropriate controls were obtained with non-immune rabbit serum or somatostatin antiserum absorbed with $60 \mu \mathrm{M}$ somatostatin. After rinsing in PBS, the slides were mounted in glycerol/PBS (3:1, vol.:vol.) and examined by epi-illumination.

As depicted in Fig. 1, 3 distinct SLI-containing cell types were identified in the amacrine cell layer of the goldfish retina and a fourth was identified in the ganglion cell layer. In addition, a prominent plexus of fine varicose fibers interspersed with larger unbranched processes $2-3 \mu \mathrm{m}$ in diameter was identified with the somatostatin antiserum in the distal half of the outer sublamina (sublamina a) of the inner plexiform layer (Figs $1 a, b$, and f). Two types of processes descended to the inner sublamina of the inner plexiform layer (sublamina b) where they formed a second plexus. One of these types was relatively thick $(1 \mu \mathrm{m}$ in diameter at the base) and arborized as it coursed through the inner plexiform layer; the other was thin and did not arborize (Fig. 1e).

Approximately $5 \%$ of the proximal row of cells in the inner nuclear layer contained SLI and there were 3 primary types. One type (SAa1) had large round perikarya with thick smooth processes that extended laterally in sublamina a of the inner plexiform layer (Figs 1a and c). The fine varicose processes in this sublamina could be traced to 
TABLE. 2. Concentrations of Somatostatin-like Immunoreactivity in Extracts of Retinas from a Variety of Vertebrate Species

\begin{tabular}{lcccc}
\hline & \multicolumn{4}{c}{ SLI (pmol) } \\
\cline { 2 - 5 } Species & Per gram & Per retina & Per gram & Per retina \\
\hline Goldfish & 13.6 & 4.0 & & 3.5 (R) \\
Carp & 1.6 & 0.5 & & \\
Frog & 9.8 & 0.5 & $62.2(\mathrm{E})$ & 7.5 (BU) \\
Chicken & 25.3 & 3.5 & $31.7(\mathrm{E})$ & $0.20(\mathrm{E})$ \\
Rat & 7.5 & 0.20 & & $0.41(\mathrm{R})$ \\
& & & & $0.68(\mathrm{~S})$ \\
& & & $4.3(\mathrm{E})$ & $0.82(\mathrm{~L})$ \\
Rabbit & 4.3 & 0.16 & & \\
Hog & 9.8 & 1.9 & $29.9(\mathrm{E})$ & \\
Cow & 39.4 & 15.1 & & \\
\hline
\end{tabular}

Data obtained in our laboratory are listed on the left. The hog and rabbit retinas were extracted in acid/acetone; the rest were extracted in $3 \%$ acetic acid. Results from other laboratories are listed on the right. BU = Buckerfield et al., 1981; E = Eskay et al., 1980; $\mathrm{L}=$ Lake and Patel, 1980; $\mathrm{R}=$ Rorstad et al., 1979, 1981; and $S=$ Shapiro et al., 1979.
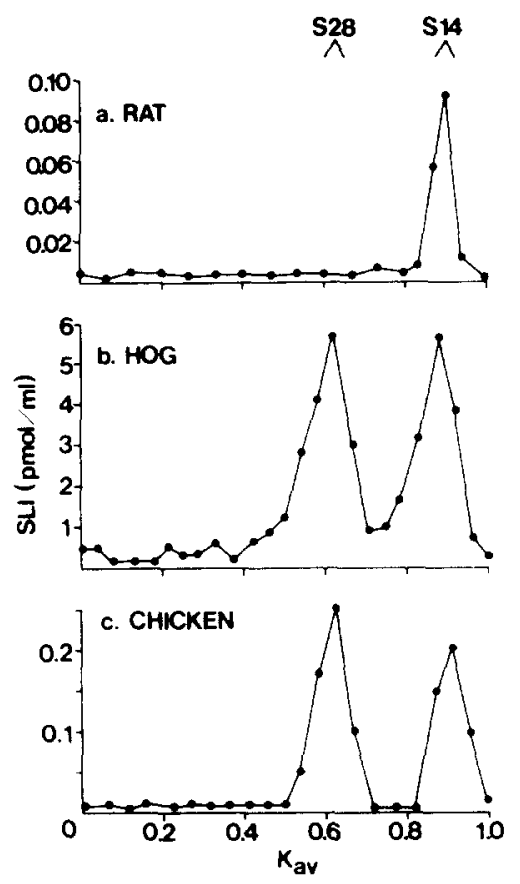

Fic. 11. Sephadex G50 sf chromatography of retinal extracts from rat (a), hog (b), and chicken (c). The elution volume $\left(\mathrm{V}_{\mathrm{c}}\right)$ had been expressed as $K_{\mathrm{a} v}$ (equal to $\mathrm{V}_{\mathrm{c}}-\mathrm{V}_{\mathrm{v}}$ ' $\left.V_{v}-V_{u}\right)$ to normalize for differences in column size. The columns were calibrated by noting the elution volume of $\mathrm{NaCl}(V)$, bovine serum albumin $\left(V_{\mathrm{u}}\right)$, somatostatin-14 (S14) and somatostatin-28 (S28). (From Marshak and Yamada, 1984).

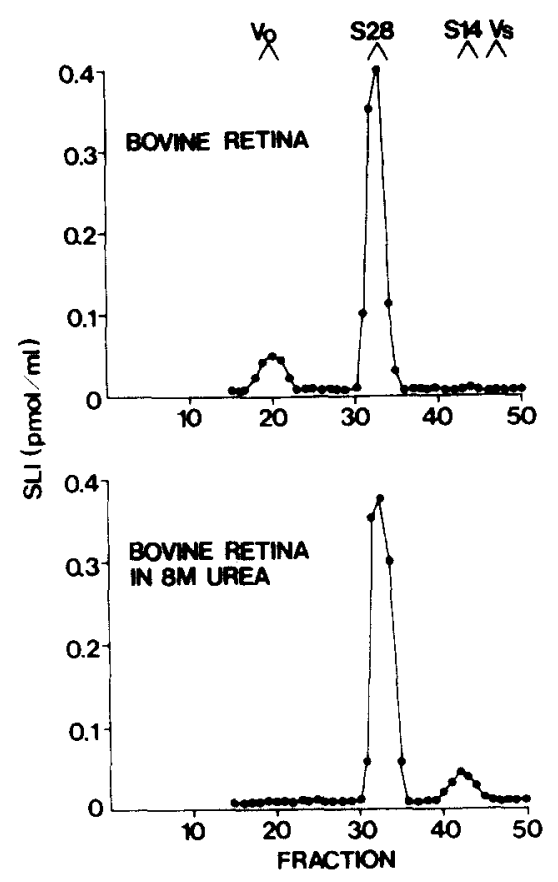

FiG. 12. Sephadex G50 chromatography of bovine retinal extracts. Extracts were chromatographed before and after $1 \mathrm{hr}$ of incubation in $8 \mathrm{M}$ urea. Both samples were applied to the same column $(1 \times 120 \mathrm{~cm})$ of Sephadex G50 $\mathrm{sf}$ equilibrated in $0.1 \mathrm{~m}$ ammonium acetate, $\mathrm{pH} 5.0$. Each $2 \mathrm{ml}$ fraction that was eluted was assayed for SLI. The column was calibrated as noted in Fig. 11. (From Marshak and Yamada, 1984). 


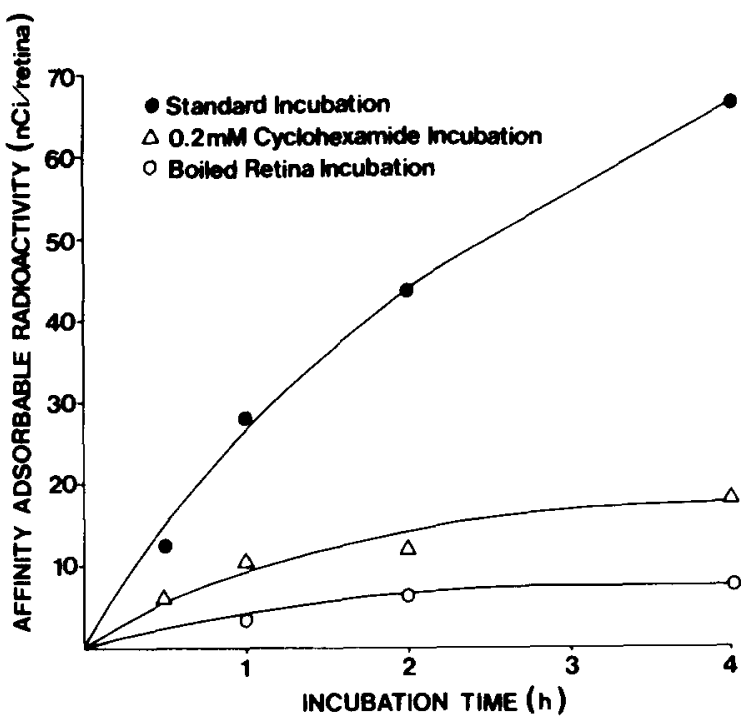

FIG. 13. Incorporation of $\left({ }^{35} \mathrm{~S}\right)$ cysteine by frog retinas into material adsorbable with somatostatin-affinity column. Three sets of 10 retinas were pulse-labeled in medium containing $\left({ }^{35} \mathrm{~S}\right)$ cysteine $(47.6 \mu \mathrm{Ci} / \mathrm{ml})$ One set of retinas was boiled prior to incubation; another set was preincubated for $15 \mathrm{~min}$ as well as pulse-labeled in medium containing $0.2 \mathrm{mM}$ cycloheximide, and the third set was incubated in standard fashion. At $0,0.5,1,2$, and $4 \mathrm{hr}$, two retinas were removed from pulse medium and extracted with $3 \%$ acetic acid. The neutralized extracts were applied to somatostatin-affinity column and eluted with $10 \%$ acetic acid. The affinity eluates were counted in a liquid scintillation spectrometer. (From Yamada and Basinger, 1982).

originate from a second cell type (SAa2) that had smaller spherical perikarya (Fig. 1b). A third cell type (SAb) had large pyriform perikarya with both thick and thin processes that descended to sublamina $b$ of the inner plexiform layer (Fig. 1e). The possibility that this cell type also gave rise to the thin varicose processes in sublamina a could not be excluded. One cell type (SGb) with somewhat flattened perikarya in the outermost layer of the ganglion cell layer (Fig. 1d) was also identified as containing SLI. It gave rise to fine smooth processes that extended along the most proximal portion of sublamina $b$ of the inner plexiform layer. The various SLI-containing cells of the goldfish retina and their processes are depicted in schematic form in Fig. 2.

\subsection{Electronmicroscopy}

To characterize the ultrastructure of the processes of SLI containing neurons in the retina

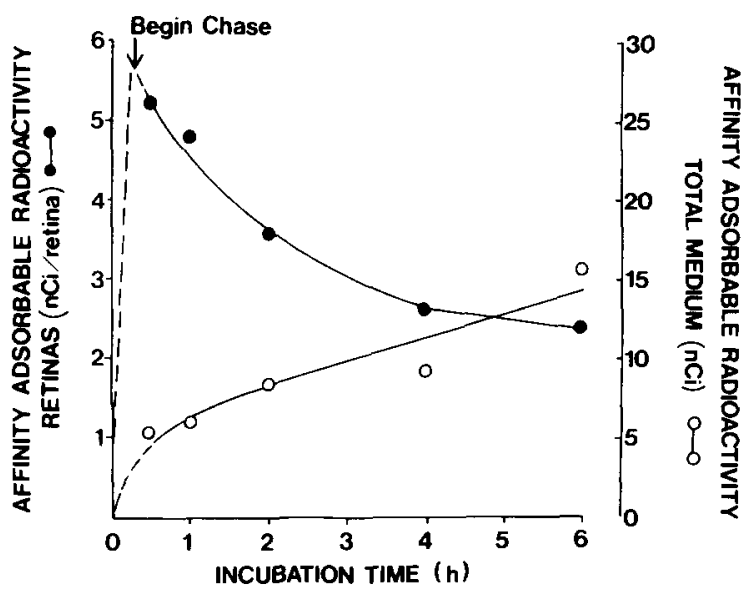

FIG. 14. Disappearance of affinity-adsorbable radioactivity from pulse-labeled retinas following chaseincubation in radioactivity-free medium. A set of 10 retinas was pulse-labeled with $\left({ }^{35} \mathrm{~S}\right) \mathrm{cysteine}$ for $15 \mathrm{~min}$ and transferred to nonradioactive chase medium. At 15, 45, 105,225 , and $345 \mathrm{~min}$ of chase incubation $(0.5,1,2,4$, and $6 \mathrm{hr}$ of total incubation), two retinas and $1 \mathrm{ml}$ of medium were removed, extracted, subjected to affinity chromatography, and assayed for radioactivity. The affinity-adsorbable radioactivity of each milliliter of medium was multiplied by the total volume of medium present in the incubation mixture at the time it was sampled to obtain a value for total affinity-adsorbable radioactivity in the medium. (From Yamada and Basinger, 1982).

and examine their synaptic connections, we extended our immunohistochemical studies to the electronmicroscopic level. For these studies goldfish retinas were fixed in $4 \%$ paraformaldehyde and $0.05 \%$ glutaraldehyde, embedded in $1 \%$ low-gelling temperature agarose and $100 \mu \mathrm{m}$ sections were cut and labeled using the peroxidaseantiperoxidase method. Serial ultrathin $(10 \mu \mathrm{m})$ sections were collected on copper grids and then coated with carbon and photographed.

Since the sections examined for electronmicroscopy were obtained at random, largely from the inner plexiform layer (Fig. 3), the majority of labeled fibers represented the beaded dendrites of the SAa2 and SAb type SLI cells. Both the thin portion and the bulbous swellings associated with these processes are depicted in Fig. 4. The synapses, as demonstrated in this figure, were identified as the parallel, straight, widely spaced, and electron dense portions of the opposing membranes on the pre- and post-synaptic cells. 


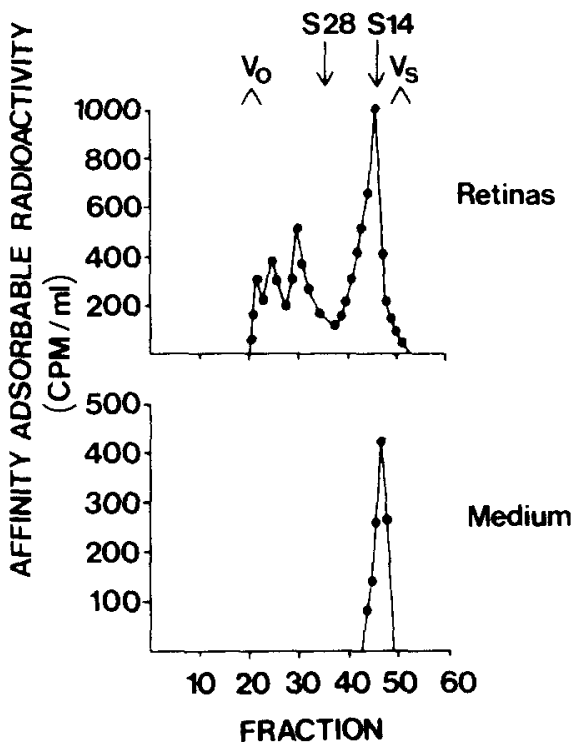

FIG. 15. Chromatographic elution of affinity-adsorbable radioactivity in retinal extracts and in chase medium. After a $30 \mathrm{~min}$ pulse-labeling in $\left({ }^{35} \mathrm{~S}\right)$ cysteine-containing medium, and a $30 \mathrm{~min}$ incubation in $30 \mathrm{ml}$ of chase medium, a set of six retinas was incubated in $2 \mathrm{ml}$ of fresh chase medium for an additional $30 \mathrm{~min}$. The retinas and medium were then extracted and affinity-adsorbed, and the affinity eluate was applied to a Sephadex G50 (superfine) column $(1 \times 120 \mathrm{~cm})$ and eluted with $0.1 \mathrm{M}$ ammonium acetate, $\mathrm{pH} 5.0$. Aliquots of eluted $2.2 \mathrm{ml}$ fractions were assayed for radioactivity. The columns were calibrated by elution of bovine serum albumin $\left(V_{0}\right)$, $\mathrm{NaCl}\left(\mathrm{V}_{s}\right)$, somatostatin $14(\mathrm{Sl})$, and somatostatin 28 (S28). (From Yamada and Basinger, 1982).

Some labeled processes also contained large densecored vesicles but these were not localized in the area adjacent to the pre-synaptic specialization. Other smaller vesicles with electron-luscent centers were also distributed throughout the processes but appeared to cluster at sites of synaptic specialization. Synaptic junctions between dendrites of various SLI containing cells and those of the other cells with processes in the inner plexiform layer are depicted in Figs 5-10. After examining a large number of sections, we observed that SLI containing retinal processes both received most of their synaptic inputs from and extended most of their outgoing synapses to other amacrine cells (Table 1). However, a substantial number of contacts were also made with ganglion cells and, to a lesser extent, bipolar

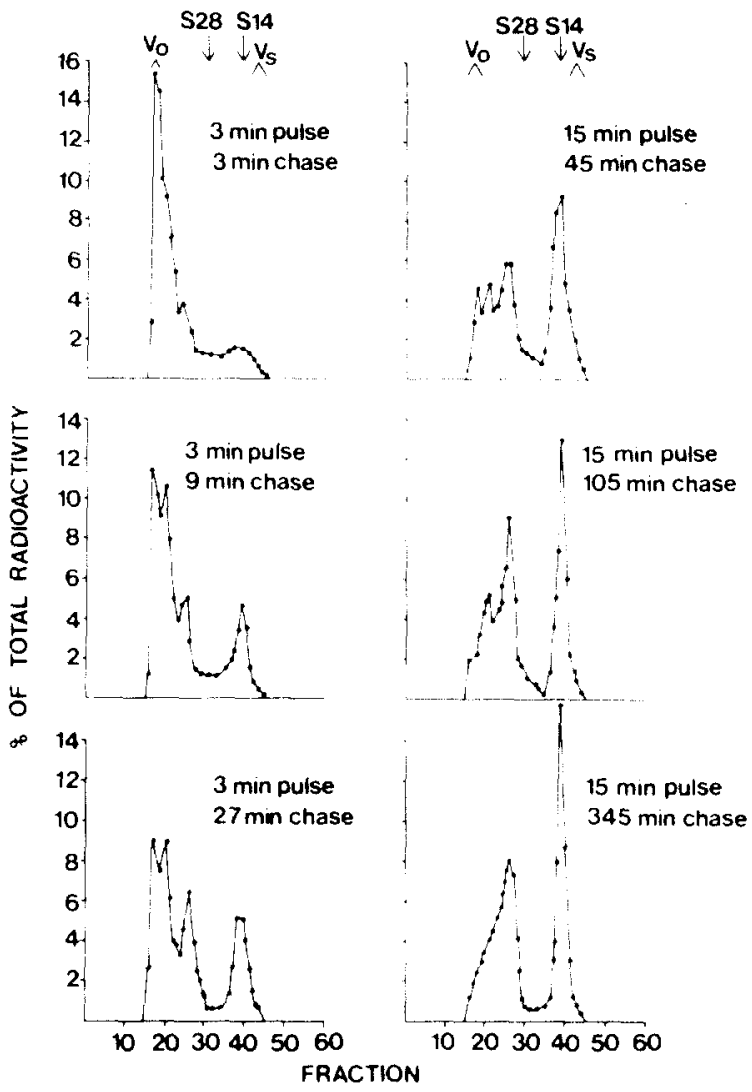

FIG. 16. Change in chromatographic elution pattern of affinity-adsorbable radioactivity obtained from retinas pulse-labeled with $\left({ }^{35} \mathrm{~S}\right)$ cysteine for $3 \mathrm{~min}$ and then incubated in chase medium for 3,9 or $27 \mathrm{~min}$, or pulselabeled for $15 \mathrm{~min}$ and incubated in chase medium for 45 , 105 , or $345 \mathrm{~min}$. The affinity eluates were chromatographed on a Sephadex G50 (superfine) column as described in Fig. 15 and fractions were assayed for radioactivity. (From Yamada and Basinger, 1982).

cells. Of particular note was that the pattern of synapses did not differ between processes in sublamina $a$ and $b$.

\section{CHARACTERIZATION OF MOLECULAR FORMS}

\subsection{Contents of SLI}

For initial biochemical characterization, we examined the contents and molecular forms of SLI in the retinas of a variety of species. Whole retinas were obtained from freshly killed animals 


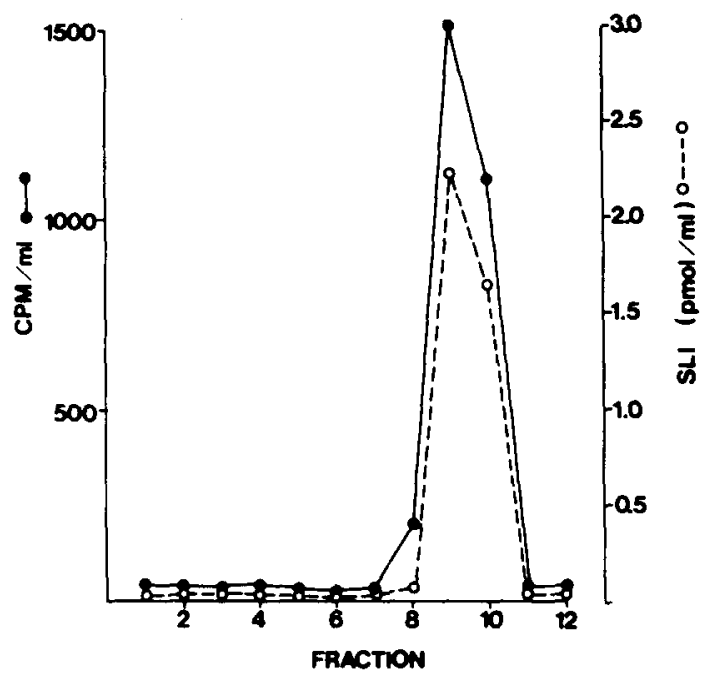

FIG 17. Elution of biosynthetic $\left({ }^{35}\right.$ S)SLI peak IV (see Fig. 15 ) and synthetic somatostatin-14 on high pressure liquid chromatography using a uBondapak $\mathrm{C} 18$ column $(0.39 \times$ $30 \mathrm{~cm})$. Fractions $(1 \mathrm{ml})$ were eluted isocratically with $29 \%$ acetonitrile in $0.1 \%$ trifluoroacetic acid at a flow rate of $1 \mathrm{ml} / \mathrm{min}$. (From Yamada and Basinger, 1982).

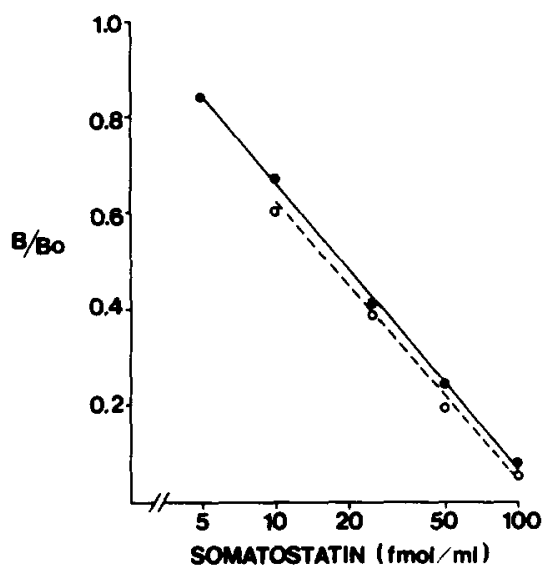

FIG. 18. Displacement of biosynthetic $\left({ }^{35}\right.$ S)SLI peak IV (O-see Fig. 15) and ${ }^{125}{ }^{-}-$Tyr $^{1}$-somatostatin $(\bullet)$ from antisomatostatin antibody in the presence of increasing concentrations of unlabeled somatostatin-14. Displacement is expressed as a ratio of bound counts at any given unlabeled somatostatin concentration (B) to bound counts in the absence of added somatostatin $\left(B_{o}\right)$. (From Yamada and Basinger, 1982). and extracted in 3\% acetic acid. In a few instances, extractions were also performed using acetone $(70 \%)$ in $3 \%$ acetic acid. The recovery of somatostatin-14 (S14) or somatostatin-28 exogeneously added to the retinas before the extraction process averaged $90-100 \%$. After extraction, aliquots were applied to gel chromatography on Sephadex G50 superfine columns equilibrated and eluted with either $0.1 \mathrm{M}$ ammonium acetate $\mathrm{pH} 5.0$ or $1 \%$ acetic acid. Each eluted fraction and the original extracts were analyzed for SLI by radioimmunoassay using an antiserum (Ab 1001) that is specific for the ring portion of S14 and cross-reacts 50\% with S28.

The concentrations of SLI in various vertebrate retinas is depicted on Table 2 . The data obtained in our laboratory generally were comparable to those reported by others. Of particular note was the high concentration of SLI present in bovine retina, an observation that proved to be useful when the purification of retinal SLI was undertaken (vide infra). It was of great interest that species as closely related as goldfish and carp had such widely varying concentrations of retinal SLI, but similar differences have been reported between Rana catesbiana and Rana pipiens (Eskay et al., 1980).

\subsection{Molecular Forms}

As in many other tissues, SLI was present in 2 major molecular forms, one that corresponded to S14 and the other that corresponded to S28 (Fig. 11). In the case of bovine retina, another molecular form eluted as a larger molecule than S28 but gel filtration of the extracts under dissociative conditions revealed this to be a artifact caused by non-covalent association of $\mathrm{S14}$ with an unidentified macromolecule (Fig. 12). The species differences in distribution of SLI into the two major molecular forms were remarkable. Whereas most of the species studied had both S28 and S14 forms, the rat had only the latter, while virtually all of the bovine retinal SLI was the former. These differences may reflect differences in post-translational processing of the somatostatin precursor in the retinas of the 2 species. 

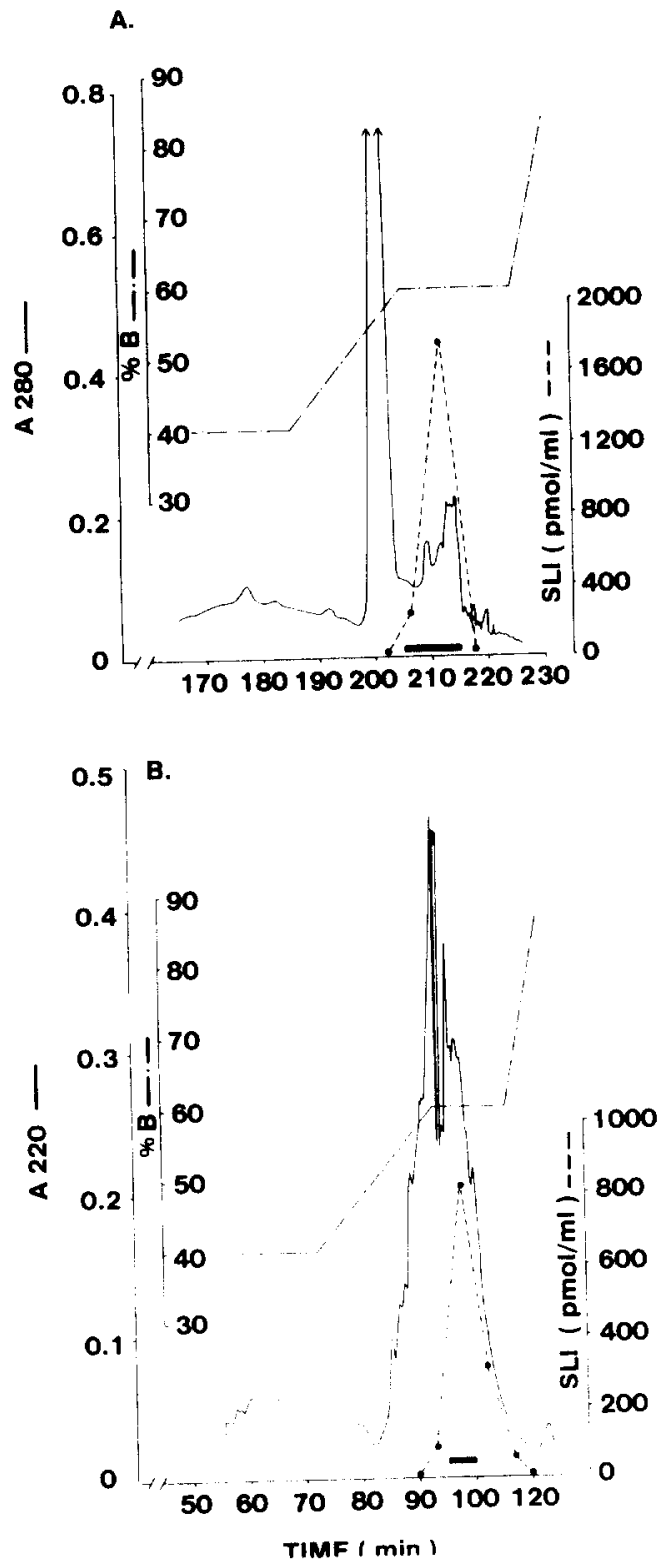

c.

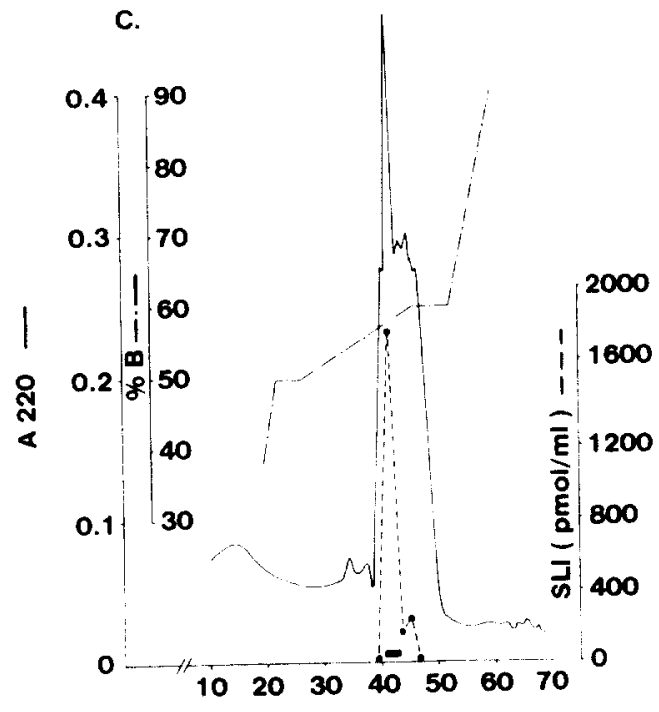

D.

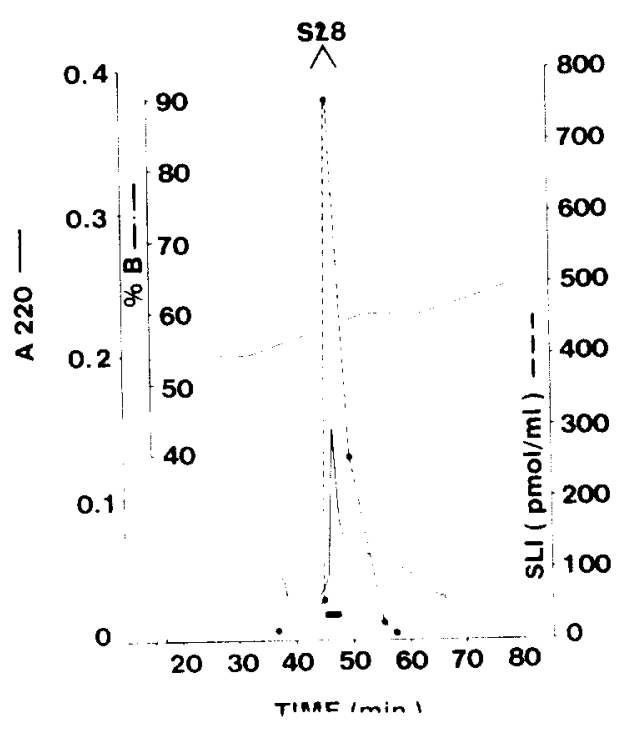

FIG. 19. Purification of bovine retinal somatostatin-like immunoreactivity (SLI) by high-pressure chromatography. After extraction with $3 \%$ acetic acid and purification by affinity chromatography, bovine retinal SLI was applied sequentially to high-pressure liquid chromatography on reverse-phase $\mathrm{C}-18$ (A) and phenyl columns (B-D). The columns were equilibrated in $0.1 \%$ trifluoroacetic acid then eluted with a stepwise gradient of $50 \%$ acetonitrile in $0.1 \%$ trifluoroacetic acid (buffer B) as indicated in each figure. A280 (A) or A220 (B - D) was monitored with a variable wavelength detector, and SLI in each fraction was quantified by radioimmunoassay. The fractions pooled for further purification $(A-C)$ or amino acid sequencing (D) are indicated by the black bars. The elution position of synthetic somatostatin octacosapeptide (S28) is indicated in D. (From Marshak et al., 1983). 
TABLE. 3. Recovery of Bovine Retinal SLI at each Step of Purification

\begin{tabular}{lcccc}
\hline & & \multicolumn{2}{c}{ Recovery (\%) } & \\
\cline { 3 - 4 } & SLI & & & Purification \\
Step & (nmol) & Step & Cumulative & \begin{tabular}{c} 
(X) \\
\hline Extract
\end{tabular} \\
Affinity & 18.6 & - & 100.0 & 1 \\
HPLC (C- 18) & $19.3 / 11.8^{*}$ & $\sim 100.0$ & $\sim 100.0$ & 150 \\
HPLC (Phenyl \#) 3.8 & 9.0 & 76.0 & 76.0 & 16,500 \\
HPLC (Phenyl \#2) & 42.2 & 42.2 & 32.2 & 46,000 \\
HPLC (Phenyl \#3) & 2.7 & 71.1 & 22.8 & 82,000 \\
\hline
\end{tabular}

*Only $11.8 \mathrm{nmol}$ of the total SLI was used for further purification; the rest was stored for future analysis. (From Marshak et al., 1983).

TABLE 4. Amino Acid Sequences of Purified Somatostatin

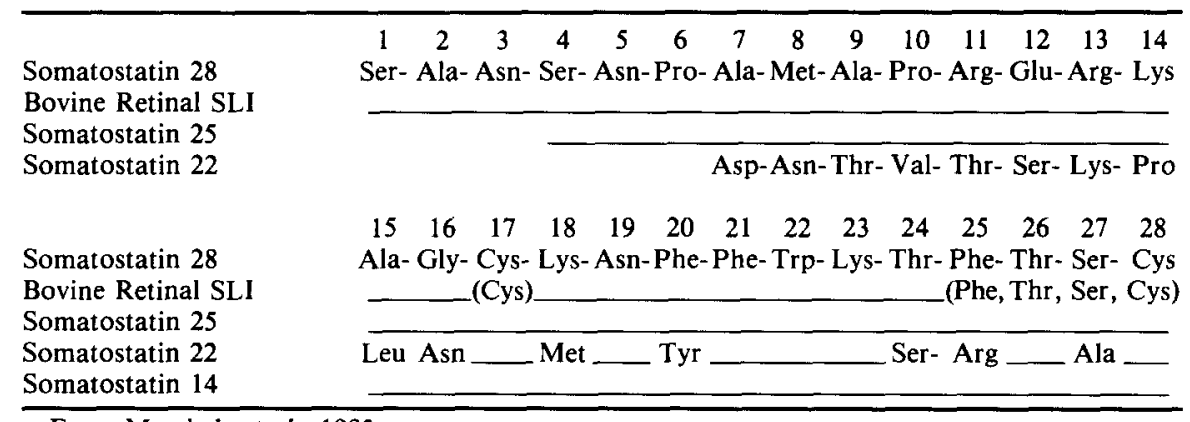

From Marshek et al., 1983.

\section{BIOSYNTHESIS OF SLI}

TABle 5. Amino Acid Composition of Bovine Retinal Somatostatin

\begin{tabular}{ccc}
\hline Amino acid & Experimental & Expected \\
\hline His & $0.1(0)$ & 0 \\
Lys & $3.0(3)$ & 3 \\
Trp* & $0.0(0)$ & 1 \\
Arg & $1.6(2)$ & 2 \\
Asx & $4.3(4)$ & 3 \\
Thr & $2.1(2)$ & 2 \\
Ser & $3.1(3)$ & 3 \\
Glx & $2.2(2)$ & 1 \\
Pro & $3.0(3)$ & 2 \\
Gly & $2.2(2)$ & 1 \\
Ala & $3.9(4)$ & 4 \\
/2Cys* & $0.9(1)$ & 2 \\
Val & $0.0(0)$ & 0 \\
Met & $0.5(1)$ & 1 \\
Ile & $0.4(0)$ & 0 \\
Leu & $0.4(0)$ & 0 \\
Tyr & $0.2(0)$ & 0 \\
Phe & $2.8(3)$ & 3 \\
\hline
\end{tabular}

*Under these hydrolysis conditions the recoveries of Cys and Trp are low. From Marshak et al., 1983.

\subsection{Label Uptake and Release}

In order to confirm that the SLI present in the retina represented the products of local peptide synthesis, and to gain insight into the posttranslational processing of somatostatin precursors, we undertook biosynthetic studies. For these experiments we used the frog retina because of its usefulness as a model for electrophysiological studies. The strategy employed for these studies was first to incorporate radioactive tracer amino acids into newly synthesized SLI, and then to immunoimmobilize the synthetic product for quantitative and qualitative studies.

Retinas were stripped free of pigmented epithelium and removed in the dark from groups of dark-adapted frogs (Rana pipiens). The retinas were then incubated in Krebs-Ringer buffer containing $8 \mu \mathrm{g} / \mathrm{ml}$ penicillin, $12 \mu \mathrm{g} / \mathrm{ml}$ 


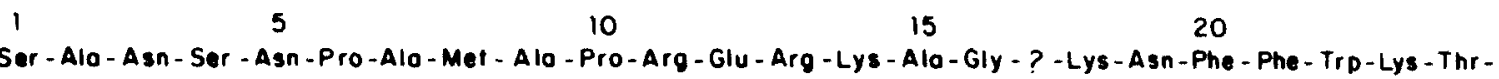

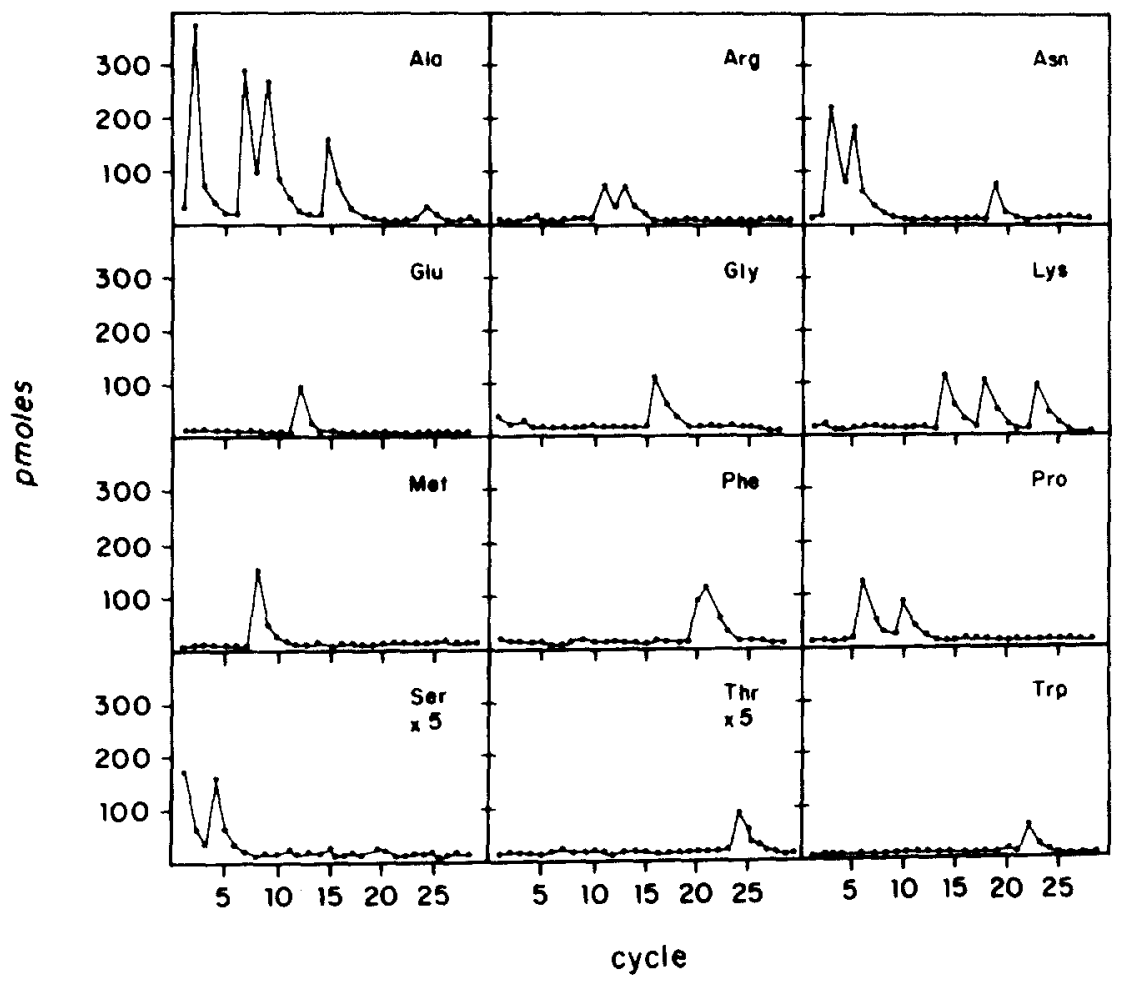

FIG. 20. Yields of phenylthiohydantoin derivatives of amino acids derived from bovine retinal somatostatin by automatic Edman degradation. Approximately $3.0 \mathrm{nmol}$ peptide (as estimated by amino acid analysis) were applied, but yield of the amino-terminal serine was only 380 pmol $(12.7 \%)$. Yields were calculated by comparison with standard after normalization for recovery, with diethylphthalate as an internal marker. Unmeasurable yields prevented amino acid sequencing beyond threonine in the 24 th cycle. The absence of a clearly identifiable derivative in the 17 th cycle is consistent with the presence of half-cysteine, which is not detected unless the native disulfide bond is chemically modified. (From Marshak et al., 1983).

streptomycin, 200 kallikrein inhibitory units $/ \mathrm{ml}$ Trasylol (FBA Pharmaceuticals, New York), and $47.6 \mu \mathrm{Ci} / \mathrm{ml}^{35}$ S-cysteine $(564 \mathrm{Ci} / \mathrm{mmol}$, New England Nuclear, Boston, Massachusetts). Following a 3 or 15 minute incubation in pulse medium, the retinas were transferred, after thorough washing, to chase incubation medium containing unlabeled L-cysteine $(0.16 \mathrm{mM})$ and casamino acids $(10 \mu \mathrm{g} / \mathrm{ml})$. At various time intervals 2 retinas and $1 \mathrm{ml}$ of culture medium were removed, extracted in $3 \%$ acetic acid and neutralized. The samples were then applied to an affinity column made with anti-somatostatin antibody (7812) linked to Affi-Gel 10. The bound radioactivity was eluted with $10 \%$ acetic acid and counted in a liquid scintillation spectrometer. The affinity eluates were then chromatographed on a Sephadex G50 superfine column $(1 \times 120 \mathrm{~cm})$ and eluted with $0.1 \mathrm{M}$ ammonium acetate buffer, pH 5.0.

As depicted on Fig. 13 affinity absorbable radioactivity (presumably newly synthesized SLI) gradually increased over the $4 \mathrm{hr}$ duration of the study and this increase could be inhibited by nearly $75 \%$ with cycloheximide, indicating that it involved a conventional ribosomal process. During the first hour, roughly $28 \mu \mathrm{Ci}$ of ${ }^{35} \mathrm{~S}$-cysteine was incorporated into SLI. Based on the specific activity of the label and assuming that at least one molecule of label was incorporated into each molecule of SLI, we calculated the basal rate of SLI synthesis to approximate $25 \mathrm{fmol} /$ retina/hr. 


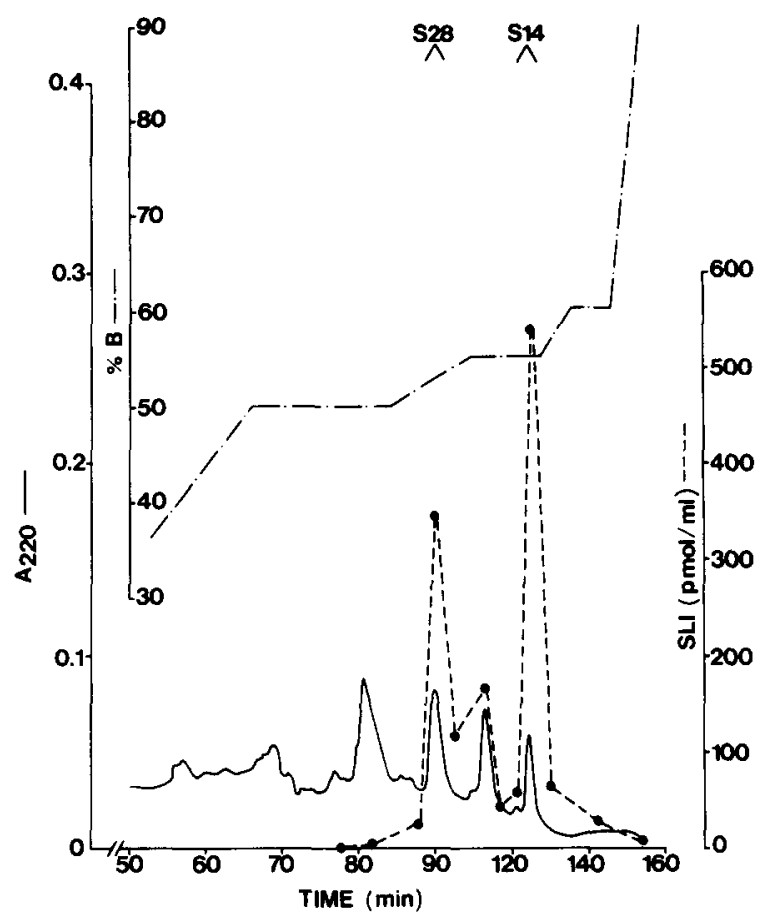

FIG. 21. Elution profile on reverse-phase phenyl highpressure liquid chromatography of SLI purified from bovine brain. Purification was achieved according to the protocol described in Fig. 19. The gradient profile is indicated. The elution positions of synthetic somatostatin tetradecapeptide (S14) and S28 are indicated at the top of the figure. (From Marshak and Yamada, 1983).

Since the total SLI content in frog retinas is roughly $500 \mathrm{fmol} /$ retina, the turnover rate of retinal SLI in the basal state appears quite low.

When pulse-chase studies were performed, affinity adsorbable radioactivity in the retinas gradually decreased with time of incubation in chase medium (Fig. 14). A complementary increase in radioactivity was observed in the culture medium. Roughly $85 \%$ of total affinityadsorbable radioactivity was recovered when the specific radioactivity of the retinas and medium were summated. This indicates that the turnover of SLI in unstimulated retinas can be accounted for largely by the basal release of the peptide. Radioactivity from the retinal extracts eluted from Sephadex G50 in 4 distinct peaks: one in the void volume (peak I, $K_{\mathrm{av}}=0.00$ ), another which coeluted with synthetic somatostatin 14 (peak IV, $\left.K_{\mathrm{av}}=0.84\right)$ and two intermediate in location (peaks II, $K_{\mathrm{av}}=0.12$; and III, $K_{\mathrm{av}}=0.32$ ) (Fig. 15). In contrast, only the peak corresponding to S14 was secreted into the culture medium. This observation is particularly important since it indicates that the radioactivity appearing in the medium did not derive from leakage of intracellular contents but from selective release of peptide. The apparently selective release of S14 despite the synthesis of other forms of SLI is curious but has been observed in other somatostatin biosynthetic systems (Chiba et al., 1987).

\subsection{Post-Translational Processing of SLI}

When the chromatographic elution profile of SLI was examined over the time course of a pulsechase experiment the distribution of radioactivity gradually shifted over time from peaks I and II to peaks III and IV (Fig. 16). However, no evidence of a shift of counts from peak III (corresponding to S28) to peak IV (corresponding to S14) was observed. Over $90 \%$ of radioactivity in pools of each of the peaks could be immunoprecipitated by incubation with anti-somatostatin antibody and goat anti-rabbit gamma globulin. Furthermore, the biochemical identity of peak IV was further confirmed by showing its co-elution with S14 on high pressure liquid chromatography (HPLC) (Fig. 17) and its parallel displacement with the standard curve by $\mathrm{S} 14$ in radioimmunoassay (Fig. 18). These findings suggest that the small molecular form of SLI synthesized in the retina is indistinguishable from $\mathrm{S} 14$ and, furthermore, that it does not derive from further post-translational modification of $\mathrm{S} 28$. The shift in radioactivity from the 2 larger peaks (I and II) to the two smaller peaks (III and IV) suggests the presence of 2 precursor forms. We cannot confirm whether the smaller precursor form (peak II) represents a processing product derived from peak $I$ or an independently synthesized precursor. The absence of these larger molecular forms of SLI on gel filtration of standard-tissue extracts may result from their relatively rapid conversion to smaller molecular forms which, in turn, accumulate in substantial quantities because of their slow turnover. 
A.

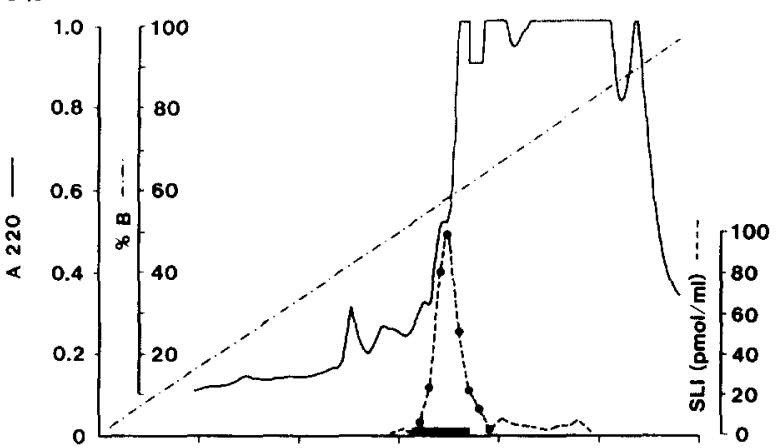

B.

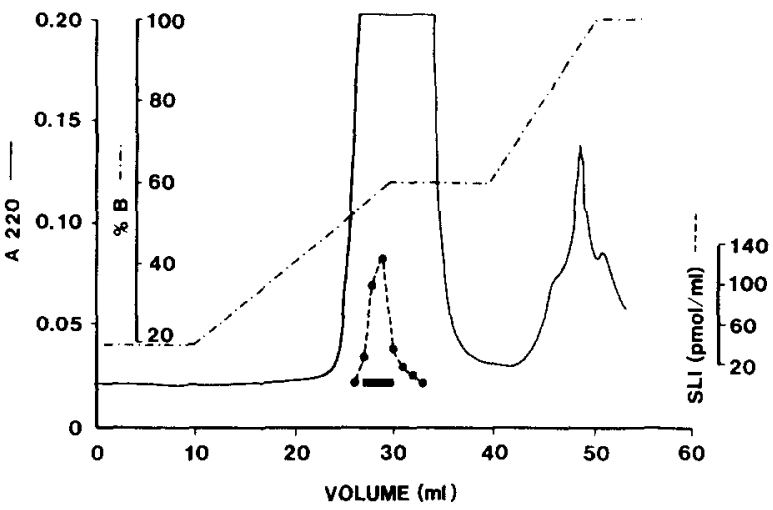

C.

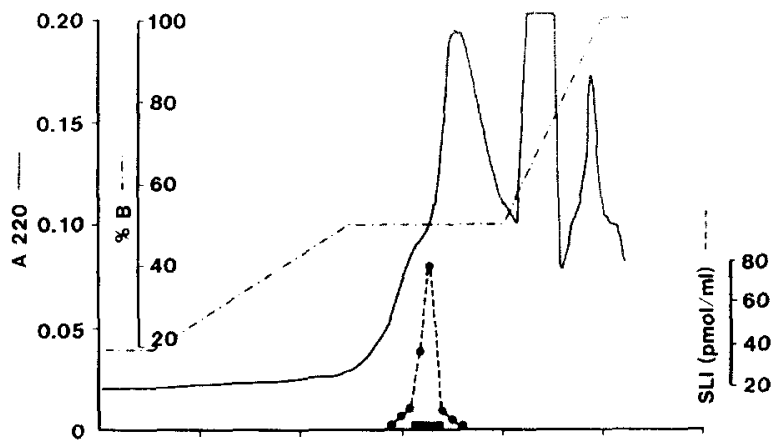

D.

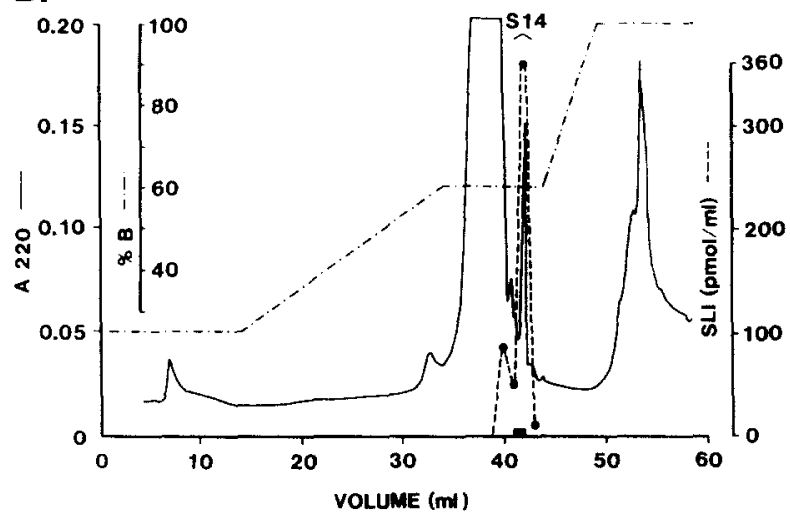

FIG. 22. Purification of frog brain SLI by HPLC. After extraction with $3 \%$ acetic acid and puritication by attunity chromatography, frog brain SLI was subjected to HPLC on reverse-phase C-18 Z-Module (A - C) and Vydac (D) columns. The columns were equilibrated in $0.1 \%$ TFA and then eluted with a stepwise gradient of $50 \%$ acetonitrile in $0.1 \%$ TFA (buffer B) as indicated in each panel. $A_{220}$ was monitored, and the SLI in each fraction was quantified by radioimmunoassay. The fractions pooled for further purification $(A-C)$ or amino acid sequencing $(D)$ are indicated by the black bars. The elution position of synthetic S14 as indicated in D. (From Takami et al., 1985).

\section{STRUCTURE OF RETINAL SOMATOSTATIN}

\subsection{Bovine Retina}

In order to provide biochemical confirmation of the immunochemical studies in the retina, we undertook the purification of retinal SLI. Determination of the correct amino acid sequences for retinal SLI is also an essential prerequisite for interpretation of physiological studies. In examining a variety of vertebrate retinas for SLI as noted above, we observed large differences in SLI concentration even among closely related species. However, on a unit basis, it was clear that the bovine retina would be the most practical source for purification of retinal SLI. In contrast to the retinas of frogs, goldfish, chickens and hogs which contain roughly equal amounts of SLI comparable to S14 and S28, nearly all of the bovine retinal SLI co-eluted with S28 on Sephadex G50 column chromatography. For purification 3000 freshly obtained bovine retinas were extracted in boiling $3 \%$ acetic acid and the neutralized extracts were applied to chromatography on affinity beads made by linking anti-somatostatin antibody to Affi-Gel 10 beads. The beads were washed sequentially with distilled water, $0.1 \mathrm{M}$ ammonium acetate $\mathrm{pH} 5.0$, and $4 \mathrm{M}$ guanidine $\mathrm{HCl}$, then the immobilized SLI was eluted with $2 \%$ trifluoroacetic acid. The affinity eluates were further purified by HPLC in a $\mu$-Bondapak C18 column and three sequential $\mu$-Bondapak phenyl columns using various gradients of acetonitrile in 


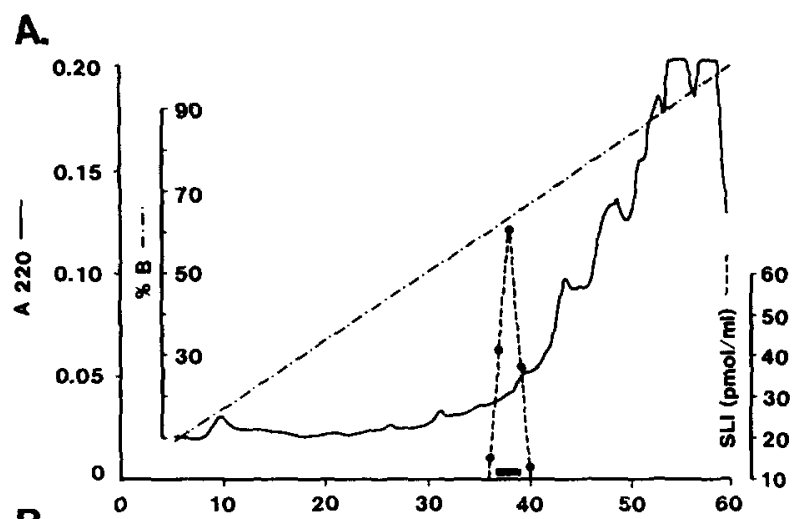

B.
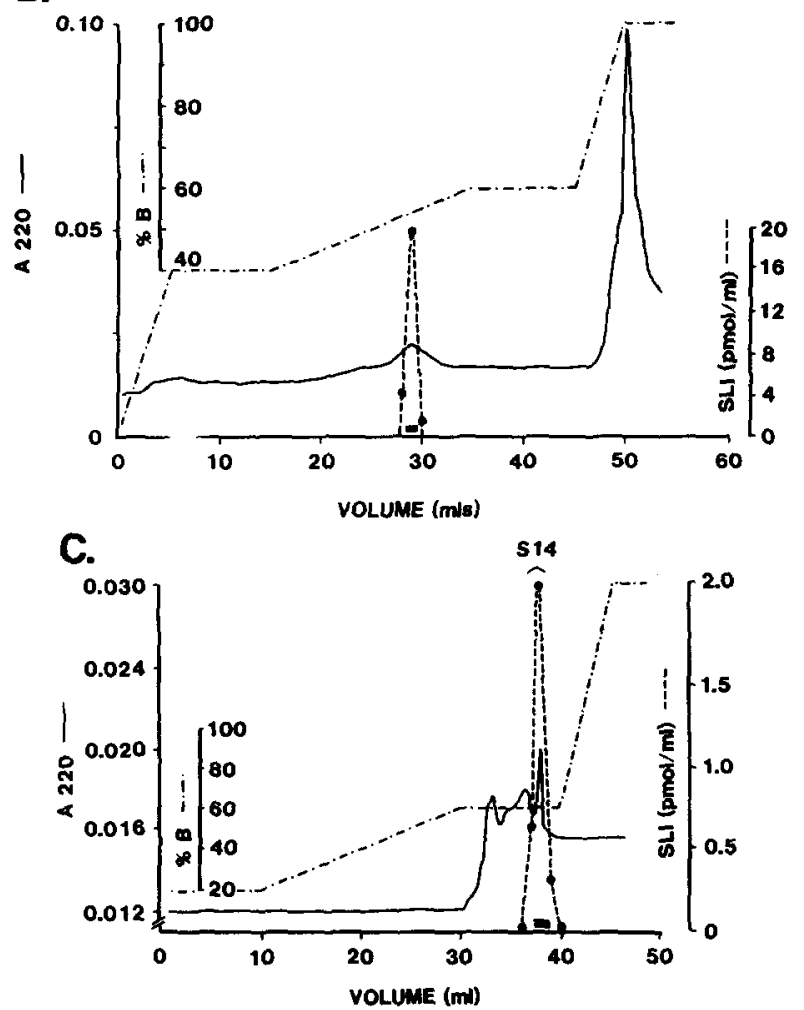

FIG. 23. Purification of frog retinal SLI by sequential HPLC on reverse phase C-18 Z-Module columns (A and B) and a $\mathrm{C}-18$ Vydac column $(\mathrm{C})$. The columns were equilibrated and calibrated as in Fig. 22. (From Takami et al., 1985).

$0.1 \%$ trifluoroacetic acid as buffer (Fig. 19). On the last phenyl HPLC column, a single sharp A220 peak was eluted and corresponded to the elution peak of SLI. This peak co-eluted with a synthetic S28 standard chromatographed on the same column. The final $1.7 \mathrm{nmol}$ of purified SLI represented a cumulative recovery of $14.4 \%$ and a purification factor of 103,000-fold (Table 3). On automated Edman degradation amino acid sequencing of the purified retinal SLI (Fig. 20), the structure of the first 24 amino acids was determined to be identical to that of S28 (Table 4) purified from hog intestine (Pradayrol et al., 1980) and from ovine (Esch et al., 1980) and porcine hypothalamus (Schally et al., 1980). The identity of the final 4 amino acids was confirmed by studies of antibody specificity and amino acid analysis (Table 5). A simultaneous partial purification of bovine brain SLI revealed HPLC peaks corresponding to both S28 and S14 (Fig. 21).

\subsection{Frog Brain and Retina}

The findings obtained with bovine retina conferred physiological relevance to functional studies in the mammalian retina employing S14 and S28, however, species differences in structure might limit interpretation of studies performed on retinas from submammalian species. The quantities of SLI extracted from submammalian retinas may be insufficient for any practical attempt at purification for the purpose of sequence analysis, however, our studies showing identical chromatographic properties on HPLC of purified SLI from retina and at least one molecular form of the peptide from brain indicated a possible solution to this problem. Detailed chemical characterization could be performed on minute quantities of purified retinal peptides and compared to their counterparts from brain which may be available in quantities sufficient for amino acid sequencing. With this logic in mind, we undertook the co-purification of frog brain and retinal SLI. We extracted the brains and retinas from 800 freshly killed frogs (Rana pipiens) in boiling 3\% acetic acid and applied the extracts sequentially to affinity chromatography on Affi-Gel 10-antisomatostatin beads, multiple $\mu$-Bondapak $\mathrm{C}$-18 $\mathrm{Z}$-module HPLC columns, and a final VYDAC C-18 HPLC column (Figs 22 and 23). Through these steps we were able to obtain $360 \mathrm{pmol}$ of brain SLI purified 110,000 -fold and $10 \mathrm{pmol}$ of retinal SLI purified 93,000-fold (Table 6). 
TABLE 6. Recovery of Frog Brain and Retinal SLI at each Step of Purification

\begin{tabular}{|c|c|c|c|c|}
\hline \multirow[b]{2}{*}{ Step } & \multirow{2}{*}{$\begin{array}{c}\text { SLI } \\
(\mathrm{nmol})\end{array}$} & \multicolumn{2}{|c|}{ Recovery $(\%)$} & \multirow{2}{*}{$\begin{array}{l}\text { Purification } \\
\text { (X) }\end{array}$} \\
\hline & & Step & Cumulative & \\
\hline \multicolumn{5}{|l|}{ Brain } \\
\hline Extract & 9.60 & - & 100 & 1 \\
\hline Affinity & $6.60 / 3.30^{*}$ & 68.8 & 68.8 & 100 \\
\hline HPLC (Z-Module \#1) & 3.23 & 97.9 & 67.3 & 11,000 \\
\hline HPLC (Z-Module \#2) & 1.34 & 41.5 & 27.9 & 25,000 \\
\hline HPLC (Z-Module \#3) & 0.78 & 58.2 & 16.2 & 60,000 \\
\hline HPLC (Vydac) & 0.36 & 46.2 & 7.5 & 110,000 \\
\hline \multicolumn{5}{|l|}{ Retina } \\
\hline Extract & 0.44 & - & 100 & 1 \\
\hline Affinity & 0.10 & 22.7 & 22.7 & 200 \\
\hline HPLC (Z-Module \#1) & 0.06 & 60.0 & 13.6 & 9,000 \\
\hline HPLC (Z-Module \#2) & 0.02 & 33.3 & 4.5 & 66,000 \\
\hline HPLC (Vydac) & 0.01 & 50.0 & 2.3 & 93,000 \\
\hline
\end{tabular}

${ }^{*}$ Only 3.30 of the $6.60 \mathrm{nmol}$ were further purified. From Takami et al., 1985.

The finally purified SLI from brain and retina co-eluted in the same fraction which was also identical to the elution fraction of standard synthetic S14. Amino acid sequencing of frog brain SLI revealed it to be identical in structure to S14 (Table 7) but different from some other somatostatins isolated from submammalian species (Table 5). Because of the identical chromatographic characteristics of the co-purified retinal and brain SLI, we inferred that the structures were likely to be identical, hence functional studies performed with S14 on amphibian retina may be interpreted in a physiologically relevant light.

\section{CONCLUSION}

Somatostatin is but one example of the many polypeptides that have been proposed as neurotransmitters in the central and peripheral nervous systems. Our experiments to characterize the anatomy and biochemistry of somatostatin in the retina hopefully have provided the groundwork for future studies to determine the physiological function of retinal somatostatin. Such studies may help to elucidate the role of peptide neurotransmitters in normal and abnormal functions of the brain. Conversely, the brain and, more specifically, the retina has provided a convenient and useful model for examining the biochemistry and molecular biology of bioactive peptides such as somatostatin.

Acknowledgements - The work presented in this manuscript represents not only my own efforts but also those of David Marshak, Scott Basinger, and Mimi Takami. I am grateful for the secretarial assistance of Lori Ennis. Support for these studies was derived from National Institutes of Health grant R01 EY05205.

\section{REFERENCES}

Ames, A., III and NesBeTt, F. B. (1981) In vitro retina as an experimental model of the central nervous system. $J$. Neurochem. 37: 867-877.

Arimura, A., Sato, H., Coy, D. H. and Schally, A. V. (1975) Radioimmunoassay for $\mathrm{GH}$-release inhibiting hormone. Proc. Soc. exp. Biol. Med. 148: $784-789$.

Bayliss, W. M. and Starling, E. H. (1902) Mechanism of pancreatic secretion. J. Physiol. (Lond.) 28: 325-353.

Brazeau, P., Vale, W., Burgus, R., Ling, N., Butcher, M., Rivier, J. and Guillemin, R. (1973) Hypothalmic polypeptide that inhibits the secretion of immunoreactive pituitary growth hormone. Science 179: $77-79$.

BRECHA, N. (1983) Retinal neurotransmitters: histochemical and biochemical studies. In: Chemical Neuroanatomy (P. C. Emson, ed.) pp. 85-129. Raven Press, New York.

Buckerfield, M., Oliver, J., Chubb, I. W. and Morgan, I. G. (1981) Somatostatin-like immunoreactivity in amacrine cells of the chicken retina. Neuroscience 6: $689-695$.

CHIBA, T., PARK, J. and YamadA, T. (1988) Biosynthesis of somatostatin in canine fundic D-cells. J. Clin. Invest. 81: $282-287$.

Costa, M., Patel, Y., Furness, J. B. and Arimura, A. (1977) Evidence that some intrinsic neurons of the 


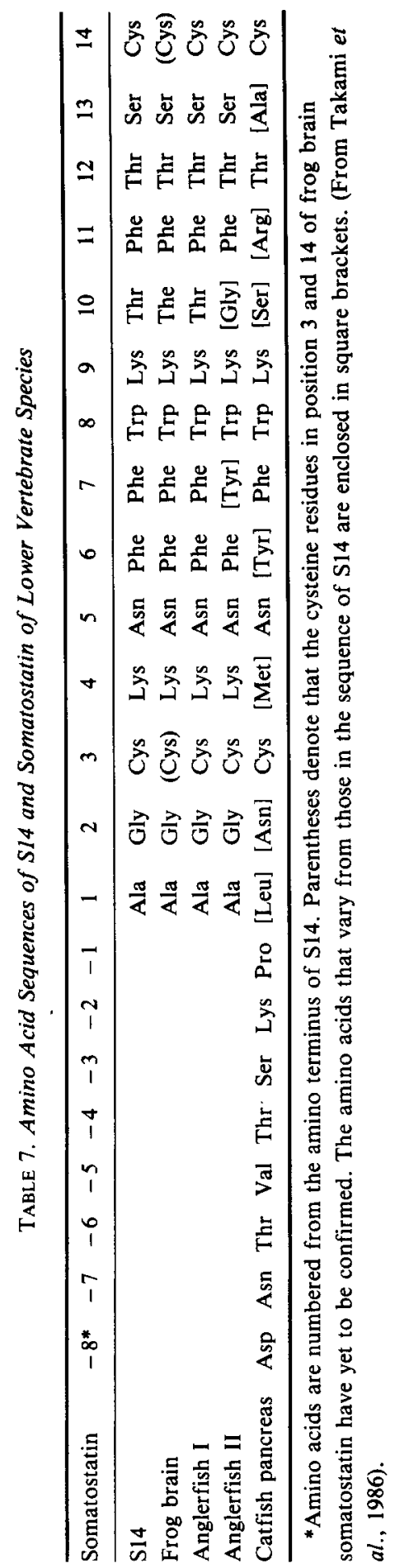


intestine contain somatostatin. Neurosci. Lett. 6: $215-222$.

DODd, J. and KeLly, J. S. (1978). Is somatostatin an excitory transmitter in the hippocampus? Nature 273: 674-675.

Epelbaum, J., Brazeau, P., Tsang, D., Brawer, J. and MARTIN, J. B. (1977) Subcellular distribution of immunoassayable somatostatin in rat brain. Nature 273: $161-163$.

Esch, F., Bohlen, P., Ling, N., Benoit, R., Brazeau, P. and Gulllemin, R. (1980) Primary structure of ovine hypothalamic somatostatin-28 and somatostatin-25. Proc. Natn. Acad. Sci. U.S.A. 77: 6827-6831.

ESKAY, R. L., LONG, R. T. and IUvONE, P. M. (1980) Evidence that TRH, somatostatin and substance $P$ are present in neurosecretory elements of the vertebrate retina. Brain. Res. 196: $554-559$.

Guillemin, R. (1976) Somatostatin inhibits the release of acetylcholine induced electrically in the myenteric plexus. Endocrinology 99: 1653-1654.

Hokfelt, T., Elde, R. P., Johannson, O., Luft, R. and Arimura, A. (1975a). Immunohistochemical evidence of the presence of somatostatin, a powerful inhibitory peptide, in some primary sensory neurons. Neurosci. Lett. 1: $231-235$.

Hokfelt, T., JohansSon, O., EFendic, S., Luft, R. and ArimurA, A. (1975b) Are there somatostatin nerves in the rat gut? Immunohistochemical evidence for a new type of peripheral nerve. Experientia 31: $852-854$.

Hokfelt, T., Elfyin, L., Elde, R., Schultzberg, M., Goldstein, M. and LuFT, R. (1977). Occurrence of somatostatin immunoreactivity in some peripheral sympathetic nonadrenergic neurons. Proc. Natn. Acad. Sci. U.S.A. 74: $3587-3591$.

IOFFe, S., HAvlicek, V., Friesen, H. and CHERnick, V. (1978) Effect of somatostatin (SRIF) and L-glutamate on neurons of the sensori-motor cortex in awake habituated rabbits. Brain Res. 153: $414-418$.

Iverson, L. L., Iverson, S. D., Bloom, F., Douglas, C., Brown, M. and VALE, W. (1978) Calcium dependent release of somatostatin and neurotensin from rat brains in vitro. Nature 273: $161-163$.

Kaneko, A. (1979). Physiology of the retina. Annu. Rev. Neurosci. 2: $169-191$.

KRISCH, B. (1978) Hypothalamic and extrahypothalamic distribution of somatostatin-immunoreactive elements in the rat brain. Cell Tiss. Res. 195: 499-513.

Krulich, L., Dhakival, A. P. S. and McCanN, S. M. (1968) Stimulatory and inhibitory effects of purified hypothalamic extracts in growth hormone release from rat pituitary in vitro. Endocrinology 83: $783-790$.

LAKE, N. and PATEL, Y. C. (1980) Neurotoxic agents reduce retinal somatostatin. Brain Res. 181: $234-236$.

Marshak, D. W., Reeve, J. R., Shively, J. E., Hawke, D., TAKAMI, M. S. and YAMADA, T. (1983) Structure of somatostatin isolated from bovine retina. $J$. Neurochem. 41: 601-606.

MARShAK, D. and YAMAdA, T. (1984) Characterization of somatostatin-like immunoreactivity in vertebrate retinas. Invest. Ophthalmol. Vis. Sci. 25: 112-115.

Marshak, D., Yamada, T. and Stell, W. K. (1984) Synaptic contacts of somatostatin-immunoreactive amacrine cells in goldfish retina. $J$. comp. Neurol. 225: 44-52.

Pardridge, W. M., Eisenberg, J. and Yamada, T. (1985) Rapid sequestration and degradation of somatostatin analogues by isolated brain microvessels. , Neurochem. 44: $1178-1184$

Pelletier, G., Labrie, F., Arimura, A. and Schali.y, A. V (1974) Electron microscopic immunohistochemical localization of growth hormone-release inhibiting hormone (somatostatin) in the rat median eminence. Am. J. Anat. 140: $445-450$

Pradayrol, L., Jornvall, J., Mutr, V. and Rıbet, A. (1980) $\mathrm{N}$-terminally extended somatostatin: the primary structure of somatostatin-28. FEBS Letts, 109: $55-58$.

Randic, M. and Miletic, V. (1978) Depressant actions of methionine-enkephalin and somatostatin in cat dorsal root neurones activated by noxious stimuli. Brain Res. 152: $196-202$.

Reichlin, S. (1983) Medical progress - Somatostatin. New Engl. J. Med. 309: 1495-1501 (first part); $1556-1563$ (second part).

Renaud, L. P., Martin, J. B. and Brazeau, P. (1975) Depressant action of TRH, LH-RH, and somatostatin on activity of central neurones. Nature 255: $233-235$.

Rorstad, O. P., Brownstein, J. J. and Martin, J. B. (1979) Immunoreactive and biologically active somatostatinlike material in rat retina. Proc. Natn. Acad. Sci. U.S.A. 76: $3019-3023$

RoRstad, O. and MARTIN, J. (1981) Neuropeptides in the visual system. In Neuropeptides: Biochemical and Physiological Studies (R. Miller, ed.), pp. 3-12. Churchill-Livingstone, New York

Schaeffer, J. M., Brownstein, J. and Axelrod, J. (1977) Thyrotropin-releasing hormone-like material in the rat retina: changes due to environmental lighting. Proc. Natn. Acad. Sci. U.S.A. 74: 3579-3581.

Schally, A., Huang, W. Y., Chang, R., Arimua, A., Redping, T., Millar, R., Hunkapiller, M. W. and HOOD, L. E. (1980) Isolation and structure of prosomatostatin: a putative somatostatin precursor from pig hypothalamus. Proc. Natn. Acad. Sci. U.S.A. 77: $4489-4493$.

Shapiro, B., Kronheim, S. and Pimstone, B. (1979) The presence of immunoreactive somatostatin in rat retina. Horm. Metab. Res. 11: $79-80$.

Stell, W., Marshak, D., Yamada, T., Brecha, N. and KARTEN, H. (1980) Peptides are in the eye of the beholder. Trends Neurosci. 30: 292-295.

Styne, D. M., Goldsmith, P. C., Burstein, S. R., Kaplan, S. L. and BrumbaCH, M. M. (1977) Immunoreactive somatostatin and luteinizing hormone releasing hormone in median eminence synaptosomes of the rat: detection by immunohistochemistry and quantification by radioimmunoassay. Endocrinology 101: $1099-1103$.

Takami, M., Reeve, J. R., JR, Hawke, D., Shively, J. E., Basinger, S. and Yamada, T. (1985) Purification of somatostatin from frog brain: Coisolation with retinal somatostatin-like immunoreactivity. J. Neurochem. 45: $1869-1874$.

Yamada, T., MarshaK, D., Basinger, S., WALSH, J., Morley, J. and Stell, W. (1980) Somatostatin-like immunoreactivity in the retina. Proc. Natn. Acad. Sci. U.S.A. 77: $1691-1695$.

YAMADA, T. and BASINGER, S. (1981) Biosynthesis-like immunoreactivity by frog retinas in vitro. $J$. Neurochem. 39: 1539-1546. 